\title{
Wer bereitet wem den Weg? Überlegungen eines Neutestamentlers zum Verhältnis zwischen Septuaginta und Neuem Testament anhand von $\mathrm{Mk}$ 1,2f.
}

\author{
FLORIAN WILK
}

Viele Bücher des Neuen Testaments (NT) nehmen fortlaufend auf die „Heiligen Schriften“ (Röm 1,2) Bezug - in Form von Zitaten und (mehr oder weniger klaren) Anspielungen, motivischen Entsprechungen und sprachlichen Reminiszenzen. ${ }^{1}$ Dabei wird in den meisten Fällen der Text der Septuaginta (LXX) vorausgesetzt. Es liegt daher auf der Hand, dass Erhebung und Deutung solcher Bezugnahmen auf die Septuaginta für die Interpretation des Neuen Testaments von Bedeutung sind.

Welche Funktion die verschiedenen Bezugnahmen innerhalb der neutestamentlichen Erzählwerke und Briefe haben und welches Gewicht ihnen demgemäß im Vollzug jener Interpretation zukommt, ist freilich im Einzelfall und im Ganzen umstritten. In diesem Streit hängt viel davon ab, wie man in den eindeutigen Fällen - bei den expliziten, d. h. durch eine Einleitungsformel als solche ausgewiesenen Zitaten - jeweils die Rezeption des Wortlauts und des Kontextes des betreffenden Schriftworts beurteilt: Sind etwaige Abweichungen von der vermuteten Vorlage als Mittel schriftgelehrter Auslegung oder als Ausdruck einer grundsätzlichen, christologisch begründeten Neubewertung der Schrift zu beurteilen? Und dient solch ein Schriftzitat allein kraft seines Wortlauts als Beleg bzw. Zeugnis einer neutestamentlichen Aussage, oder erfüllt es seine Aufgabe erst dadurch, dass es den ursprünglichen Kontext des zitierten Schriftwortes ins Gedächtnis ruft?

Derartige Fragen lassen sich nicht pauschal beantworten, sondern bedürfen einer gründlichen Prüfung jedes Einzelfalls. Andererseits ermöglicht bereits ein markanter Einzelfall Rückschlüsse darauf, wie aus neutestamentlicher Sicht das Verhältnis zwischen Septuaginta und Neuem Testament zu beschreiben ist.

Es sei betont: aus neutestamentlicher Sicht. Die Septuagintaforschung ist ja längst keine Hilfswissenschaft mehr - glücklicherweise. Schon in der Sicht der evangelischen Theologie hat sie eine umfassende Aufgabe. Sie muss, um mit Robert Hanhart zu sprechen, „Ursprung, Geschichte und Bedeutung der griechi-

1 Zur Definition der genannten vier Kategorien vgl. F. WiLk, Die Bedeutung des Jesajabuches für Paulus (FRLANT 179), Göttingen 1998, 9.266f. 
schen Gestalt des Alten Testaments“ erkunden und darstellen. ${ }^{2}$ Dabei gilt es eine Fülle von Aspekten zu berücksichtigen: die Eigenart der Sprachgestalt, das Verhältnis zur hebräisch-aramäischen Vorlage (soweit vorhanden oder rekonstruierbar) sowie ggf. den Charakter der Übersetzung, die Bezüge auf Zeitgeschichte und Lebenswelt, die Widerspiegelung exegetischer Verfahrensweisen sowie halachischer und theologischer Auffassungen, die Funktion der Septuagintaschriften für die Erstrezipienten (soweit erkennbar), die Überlieferung des Septuagintatextes, dessen Überarbeitungen und Rezensionen sowie erneute Übertragungen in weitere Sprachen, die Kanonisierung, die reiche Wirkungs- und Rezeptionsgeschichte der Septuaginta etc. Benachbarte Wissenschaften wie Judaistik, Alte Geschichte, Klassische Philologie und Religionsgeschichte betrachten sie unter zusätzlichen oder anderen Gesichtspunkten. Und bei alledem ist die innere Vielfalt der Septuaginta, in der zahlreiche ursprünglich eigenständige, über einen langen Zeitraum entstandene und unterschiedlich ausgerichtete Übersetzungen und Schriften versammelt sind, zu würdigen. Septuagintaforschung ist demnach ein interdisziplinäres und im weiteren Wortsinn ,ökumenisches“ Unterfangen.

Wenn also im Folgenden ein Neutestamentler - und das heißt: ein christlicher Bibelwissenschaftler - exemplarisch das Verhältnis zwischen Septuaginta und Neuem Testament bedenkt, so geschieht das im Bewusstsein der Begrenztheit der eigenen Kompetenz im Blick auf das Thema und der Bedingtheit der eigenen Wahrnehmung durch die genannte Perspektive.

Als markantes Beispiel eignet sich das Zitat in Mk 1,2f. Einerseits hat es im Rahmen des Evangeliums nach Markus (MkEv) insofern eine hervorgehobene Stellung, als es unmittelbar auf dessen ersten, prädikatlosen Satz folgt und demgemäß - im Unterschied zu allen übrigen Schriftzitaten in diesem Buch - ,nicht von einer Erzählfigur, sondern vom Erzähler selbst gesprochen “3 wird. Andererseits gibt es kaum ein anderes Schriftzitat im Neuen Testament, dessen Auslegung ähnlich vielfältige Probleme bereitet. Seine Untersuchung lässt deshalb in besonderer Weise Aufschluss zu der genannten Grundsatzfrage erwarten.

Die Fragen, die das Zitat in Mk 1,2f. im Zuge einer exegetischen Untersuchung aufwirft, lassen sich verschiedenen, aber miteinander verknüpften Problembereichen zuordnen:

a) Wortlaut: Wie lautet der wahrscheinlich älteste Text von Mk 1,1-4?

b) Textgestalt: Welche Schriftworte werden hier auf der Basis welcher Textfassungen zusammengestellt? Inwieweit wird dabei der Wortlaut der Vorlage(n) modifiziert?

c) Syntax und Struktur: Welche Sätze liegen in Mk 1,1-4 vor, und wie sind sie (syntaktisch und logisch) miteinander verknüpft?

d) Referenz: Auf welche realen Größen verweisen die im Zitat genannten Personen?

2 Vgl. R. Hanhart, Septuaginta, in: W. H. Schmidt / W. Thiel / R. Hanhart (edd.), Altes Testament (GKT 1), Stuttgart 1989, 176-196, hier 1786.

3 B. van IERSEL, Markus. Kommentar, Düsseldorf 1993, 81. 
e) Sachaussage: Was meint die Rede vom „Anlegen“ und vom „Bereiten“ des "Weges"?

f) Herkunft: Stammt das Zitat ganz oder teilweise aus vor- oder frühchristlicher Tradition? Wie ist in diesem Zusammenhang das Verhältnis zu Mt 3,3 // Lk 3,4ff. und Mt 11,10 // Lk 7,27 zu beurteilen?

g) Reichweite: Für welchen Teil des MkEv ist das Zitat relevant?

Diesen Fragen ist im Folgenden nachzugehen. ${ }^{4}$ Dazu soll - nach der Textkritik - zunächst geklärt werden, welches Verständnis eine inner-neutestamentliche Analyse des Textes nahe legt. Auf dieser Basis lässt sich dann zeigen, zu welchen Ergänzungen, Vertiefungen und/oder Korrekturen dieser Auslegung der Blick auf Wortlaut und ursprünglichen Kontext der zitierten Schriftworte führt.

\section{Zur Textkritik in Mk 1,1-4}

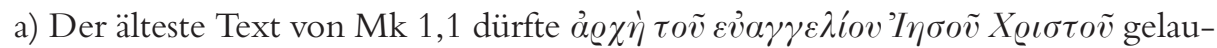
tet haben. Dieser Wortlaut ist durch den Sinaiticus (in seiner originalen Gestalt), einige weitere Hss. sowie Origenes und damit recht gut bezeugt. ${ }^{5}$ Zudem stellt er gegenüber der um viõ $9 \varepsilon \circ \tilde{v}$ ergänzten Lesart nicht nur die lectio brevior, sondern auch die lectio difficilior dar; denn während der Gottessohn-Titel für die markinische Darstellung Jesu zentrale Bedeutung hat (vgl. 1,10; 3,11; 5,7; 9,7; 14,61; 15,39, ferner 13,32), ${ }^{6}$ ist der Ausdruck "Jesus Christus" im MkEv sonst nicht belegt. ${ }^{7}$

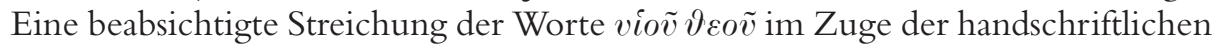
Überlieferung ist deshalb unwahrscheinlich. Auch die Annahme eines mechanischen Schreibfehlers hat aus orthographischer Sicht wenig für sich, selbst dann, wenn man die (nicht ganz einheitliche) Praxis, nomina sacra abzukürzen, in Rech-

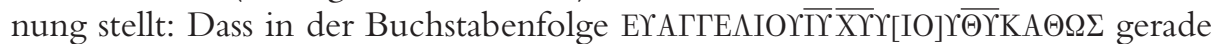
die Sequenz $\mathrm{Y}[\mathrm{IO}] \mathrm{r} \overline{\mathrm{\Theta r}}{ }^{8}$ ausgefallen sein soll, liegt keineswegs nahe. ${ }^{9}$ Letztere wird vielmehr ein sekundärer, das Profil des MkEv schärfender Zusatz sein. ${ }^{10}$

b) Die Textkritik zu Mk 1,2f. lässt sich nur im Zusammenhang mit der Ermittlung der Textgrundlage des Zitats durchführen; und dafür muss der handschrift-

4 Mit mehreren der angeführten Fragen hängt darüber hinaus das viel diskutierte Problem der Deutung des Worts $\grave{\alpha} \varrho \chi \eta^{\prime}$ in Mk 1,1 zusammen. Es muss deshalb im Folgenden mit bedacht werden.

5 Demgegenüber findet sich der Text ohne 'I Epiphanius; er ist also viel zu schwach bezeugt, um als ursprünglich gelten zu können.

6 Vgl. dazu F. WiLk, Jesus und die Völker in der Sicht der Synoptiker (BZNW 109), Berlin/New York 2002, 56-58.

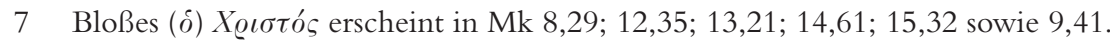

8 Eine Abkürzung von viov zu $\overline{\Upsilon Y}$ ist (wie $\mathrm{z}$. B. der Befund in $\mathfrak{P}^{66}$ zeigt) möglich, aber nicht selbstverständlich.

9 Wesentlich näher läge der Augensprung von $\varepsilon \dot{v} \alpha \gamma \gamma \varepsilon \lambda i$ ov (über viov hinweg) zu $\vartheta \varepsilon \sigma \tilde{v}$.

10 Ferner vgl. B. M. Metzger, A Textual Commentary to the Greek New Testament, Stuttgart $^{2} 1994,62$. 
liche Befund zu den relevanten alttestamentlichen Stellen berücksichtigt werden. Siehe dazu u. in Abschnitt 5.

c) In Mk 1,4 dürfte der längere, durch den Sinaiticus und einige weitere Hss. bezeugte Text den Ausgangspunkt der handschriftlichen Überlieferung darstel-

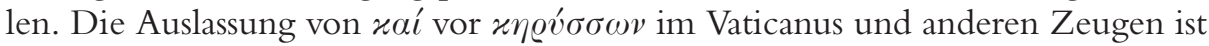
ebenso als sekundäre Glättung zu beurteilen wie die Tilgung des Artikels $\delta$ vor $\beta \alpha \pi \tau i \zeta \zeta \omega v$ im Alexandrinus und vielen anderen Handschriften.

\section{Zur Syntax in Mk 1,1-4}

Die Wort- und Satzfolge in Mk 1,1-4 weist eine Reihe von Interpretationsproblemen auf. Im Folgenden sollen diese Probleme ${ }^{11}$ sukzessive dargestellt und - vor dem Hintergrund des Sprachgebrauchs und im Zusammenhang der Jesuserzählung des Markus - bedacht werden.

a) Wie ist die Wendung „Evangelium Jesu Christi“ zu verstehen? Vom markinischen Wortgebrauch her (vgl. Mk 1,14.15; 8,35; 10,29; 13,10; 14,9) wird man „Evangelium“ sicher nicht als Titel des vorliegenden literarischen Werkes, sondern als Bezeichnung der mündlich verkündigten Heilsbotschaft aufzufassen haben. Jesus erscheint im MkEv zunächst als Träger solcher Heilsbotschaft. ${ }^{12}$ Späterhin weist der Begriff „Evangelium“ jedoch darüber hinaus in die Zeit der nachösterlichen, weltweiten Mission $(13,10)$, bei der auch Stoffe der Jesuserzählung zur Sprache kommen (14,9); daher lässt sich Jesus - zumal in der Verbindung mit dem Prädikat „Christus“ - auch als Gegenstand jener Botschaft verstehen. ${ }^{13}$ Demgemäß wirkt sich die Entscheidung über die Deutung des Genitivs ,Jesu Christi“ unmittelbar

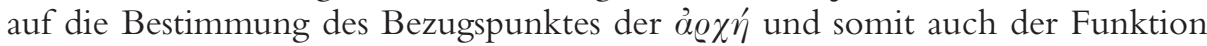

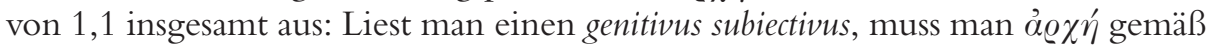
V. $14^{14}$ jedenfalls primär auf das der Verkündigung Jesu vorausgehende Auftreten des Täufers beziehen; V. 1 erscheint dann als Überschrift zu den ersten Versen des MkEv: ${ }^{15}$ Der „Ursprung“ der Verkündigung des Evangeliums durch Jesus Christus liegt darin, dass zunächst der Täufer am Jordan auftritt und ,,den Stärkeren“ ankündigt (V. 4-8), sodann Jesus die Taufe des Johannes empfängt, unter Begabung mit dem Geist zum Gottessohn ernannt wird und in der Wüste der Versuchung durch den Satan widersteht (V. 9-13). Liest man hingegen einen genitivus obiectivus, so

11 Vgl. dazu E. Boring, Mark 1:1 and the Beginning of the Gospel, in: Semeia 52 (1980), $43-$ 81, hier 47-50.

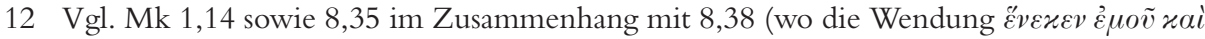

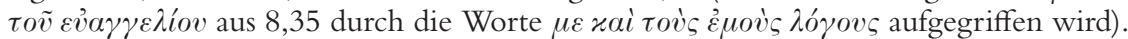

13 Aus Mk 10,29 (und dann auch aus 8,35) kann man dementsprechend den Schluss ziehen, dass das Evangelium in nachösterlicher Zeit Jesus Christus gleichsam repräsentiert.

14 Dort heißt es: „Nach der Auslieferung des Johannes aber kam Jesus nach Galiläa und verkündigte das Evangelium Gottes."

15 Mk 1,1 wäre dann in Analogie zu Hos 1,2a zu verstehen - einem Satz, der allerdings gerade nicht am Beginn des Hoseabuches steht. 
ergeben sich zwei Möglichkeiten. V. 1 ist dann entweder ,als zusammenfassende Überschrift zu [V.] 1-15 anzusehen“: ${ }^{16}$ Der „Anfang“ des Evangeliums von Jesus Christus ist mit den in der Evangeliumsverkündigung Jesu gipfelnden Ereignissen gegeben. Ebenso gut lässt sich aber auch die gesamte Jesuserzählung des Markus

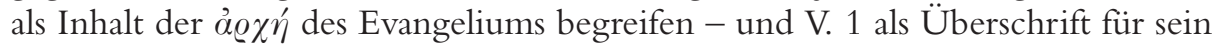
ganzes Buch: ${ }^{17}$ Die „Grundlegung“ des Evangeliums von Jesus Christus vollzieht sich im Zusammenhang von Jesu Wirken und Geschick, der von der Taufe bis ins leere Grab reicht und durch die Kommentare des in Kamelhaare gekleideten Täufers (1,6-8) und des weiß gewandeten Jünglings (16,5-7) gerahmt wird. Der

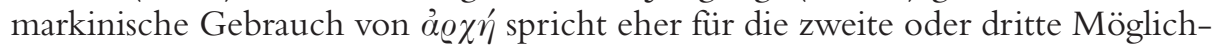
keit, bezeichnet das Wort doch sonst im MkEv den in die nachfolgend benannte Ereignisfolge $(13,8)$ oder Schöpfungswirklichkeit $(10,6 ; 13,19)$ eingeschlossenen Anfangspunkt - und nicht einen außerhalb ihrer liegenden Ursprung. Eine definitive Entscheidung allein aufgrund dieser spärlichen Beleglage ist freilich nicht möglich.

b) Wie ist Mk 1,3 mit V. 2 verknüpft? Da in V. 3 ein syntaktischer Neueinsatz

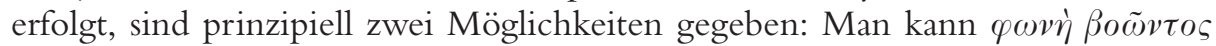

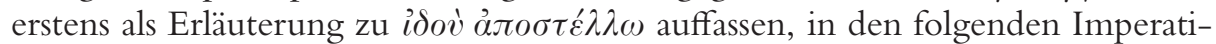
ven also das Sendungswort an den „Boten“ aus V. 2b sehen. Dann wäre in V. 2c und V. 3b-c von ein und demselben Vorgang - oder doch von eng aufeinander bezogenen Vorgängen - die Rede, sodass der Weg des in der 2. Person Sing. Angesprochenen mit dem Weg des „Herrn“ identisch wäre oder jedenfalls in unmittelbarem Zusammenhang stünde. Man müsste dabei freilich die Unschärfe in Kauf nehmen, dass jene Imperative in der 2. Person Pl. formuliert, also eigentlich an eine Mehrzahl von Personen gerichtet sind. Zweitens lässt sich $\varphi \omega v \eta \dot{\beta} \beta \tilde{\omega} \nu \tau o \varsigma$ als Apposition zum Relativpronomen ös in V. 2c deuten; ${ }^{18}$ dann kommt in den nachfolgenden Aufforderungen die Botschaft jenes $\ddot{\alpha} \gamma \gamma \varepsilon \lambda \partial \varsigma$ zur Sprache, der seine Aufgabe der Wegbahnung dadurch erfüllt, dass er andere dazu anhält, ihrerseits „,den Weg des Herrn“ zu bereiten. Ob in diesem Fall der Weg des in V. 2b-c Angesprochenen mit dem ,Weg des Herrn“ identisch ist, bliebe allerdings ebenso offen wie die Frage, welches Kollektiv der Bote anspricht. Ein etwas glatterer Gedankengang ergibt sich bei der erstgenannten Deutung; der Befund ist jedoch keineswegs eindeutig. Auch die Aufnahme der Wendung ,,in der Wüste“ aus dem

16 D. LührmanN, Das Markusevangelium (HNT 3), Tübingen 1987, 33.

17 Die Annahme, $\grave{\varrho} \chi \eta^{\prime}$ verweise allein auf das in Mk 1,2f. angeführte Gotteswort (so z. B. M. A. Tolbert, Sowing the Gospel. Mark's World in Literary-Historical Perspective, Minneapolis 1989, 243; ähnlich R. Kampling, Israel unter dem Anspruch des Messias. Studien zur Israelthematik im Markusevangelium [SBB 25], Stuttgart 1992, 43), scheitert am syntaktischen Befund: In 1,1 liegt ja keine (prädikative) Aussage vor, die durch ein mit $\varkappa \alpha \vartheta \dot{\varsigma} \gamma^{\prime} \dot{\gamma} \varrho \alpha \pi \tau \alpha \iota$ angeschlossenes Zitat in der Schrift verankert (so 9,13; 14,21, vgl. 14,27) oder aus ihr mit Inhalt gefüllt (so 7,6f.) werden könnte, sondern ein prädikatloser Titel. Ferner s. u. Absatz 2.e).

18 H. Lausberg, Minuscula philologica (III): Die prooemiale Periode des Evangeliums nach Markus (1,2-4), in: NAWG.PH 1979, 69-77, hier 71.74. 
Zitat mit Bezug auf Johannes den Täufer in V. 4 klärt die Sachlage nicht; diese

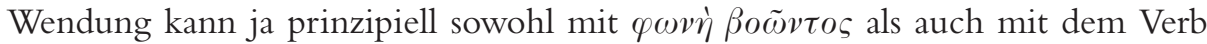
$\varepsilon ं \tau о \iota \mu \alpha ́ \alpha \alpha \tau \varepsilon$ verknüpft werden. ${ }^{19}$

c) Wie ist die Wortfolge in der ersten Hälfte von $\mathrm{Mk} 1,4 \mathrm{zu}$ interpretieren? Sieht man durch xaí die Partizipien $\beta \alpha \pi \tau i ́ \zeta \omega v$ und $\varkappa \eta \varrho v \sigma \sigma \omega v$ verbunden, sind beide dem Artikel $\delta$ zuzuordnen, sodass V. 4 besagt: „Es trat auf Johannes, der in der Wüste taufte und (der) eine Taufe ... verkündigte." Versteht man hingegen $\delta \beta \alpha \pi \tau i \zeta \zeta \omega v$ als Titel des Johannes, so wird $\varkappa \eta \varrho v \sigma \sigma \omega v$ durch $\varkappa \alpha i ́$ explizierend an

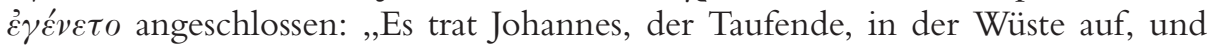
zwar indem er eine Taufe ... verkündigte." Für die zweite Möglichkeit sprechen sowohl die Parallelen zur Bezeichnung des Johannes als $\delta \beta \alpha \pi \tau i \zeta \zeta \omega v$ in 6,14.24 als auch der Sachverhalt, dass ,,in der Wüste“ "besser allgemein als Ort seines Auftretens denn (nur) als Ort seines Taufens zu verstehen ist - zumal Letzteres nach V. 5 ,im Jordan" stattfindet.

d) Wie ist die Wendung „Taufe der Umkehr zur Vergebung der Sünden“ in Mk 1,4 zu deuten? Der neutestamentliche Sprachgebrauch lässt sowohl die Vorstellung einer Taufe, die Vergebung der Sünden bewirkt (vgl. Apg 2,38), als auch die einer zur Vergebung der Sünden führenden Umkehr (vgl. Lk 24,47) zu. Angesichts dessen, dass Jesus selbst in Mk 1,15 zur Umkehr ruft und in 2,1-12 als derjenige auftritt, der als „Menschensohn“ die ,Vollmacht hat, auf Erden Sünden zu vergeben“, kommt für 1,4 aber wohl nur die zweite Möglichkeit in Betracht. In der Taufe durch Johannes kommt dann - als einer Taufe mit Wasser (vgl. V. 8) die Umkehr zur Darstellung, welche die Getauften, anhebend mit ihrer Taufe, vollziehen.

e) Wie ist das Schriftzitat Mk 1,2f. in den Rahmen aus V. 1 und V. 4 eingebunden? Erneut stehen sich zwei Möglichkeiten gegenüber: ${ }^{20}$ Einerseits könnte das Zitat an die „Kopfzeile“ V. 1 angeschlossen sein. Für diese Verknüpfung spricht

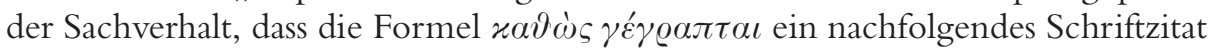
im NT regelmäßig an das Voranstehende anschließt (vgl. Lk 2,23 u. ö.), ${ }^{21}$ während Belege für einen über das Zitat hinaus nach vorne weisenden Sinn dieser

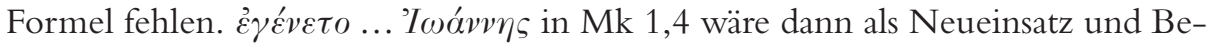

19 Vgl. zu dieser Alternative einerseits Mt 3,3 (vgl. V. 1 [s. u. Absatz 4]), andererseits 1QS $8,13 \mathrm{f}$.

20 Als syntaktisch selbständige Einheit lässt sich Mk 1,2f. innerhalb des Rahmens aus V. 1

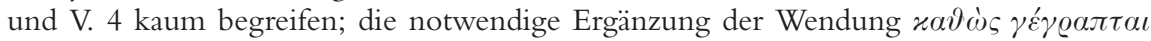
zu einem eigenen Satz müsste vergleichbaren Fällen (etwa Röm 10,15; 1Kor 2,9) entsprechend aus dem Kontext konstruiert werden, und dafür kämen nur V. 1 und V. 4 als Referenzpunkte in Betracht. Andererseits geht es auch nicht an, V. 2 mit V. 1, V. 3 hingegen mit V. 4 zu verknüpfen; die Zitationsformel in V. 2a bindet V. 2b-3c ja zu einem Schriftzitat zusammen.

21 Vgl. P. Katz, Wie einer der Propheten? Das biblische Markusevangelium als Darbietung eines «Vorevangeliums», in: ThZ 58 (2002), 46-60, hier 48. Dabei kann die Zitationsformel im Einzelfall auch nachgestellt werden wie in Röm 2,24. 
ginn der eigentlichen Erzählung zu verstehen. ${ }^{22}$ Allerdings erscheint der Anschluss eines Schriftzitats an eine prädikatlose Wendung, wie sie in V. 1 vorliegt, ${ }^{23}$ höchst ungewöhnlich. ${ }^{24} \mathrm{Im} \mathrm{MkEv}$ wird die Formel sonst anders verwendet, nämlich zur nachträglichen Kennzeichnung einer Aussage über das Geschick Elijas bzw. des Menschensohns als exegetischer Konklusion aus der Schrift $(9,13 ; 14,21 \mathrm{a}) .{ }^{25}$ Demgemäß kommt auch die Verbindung des Zitats mit 1,4 in Betracht. Für den asyndetischen Anschluss eines mit dem Verb beginnenden Hauptsatzes an einen $x \alpha \vartheta \omega ́ s-$ Satz gibt es im NT durchaus Analogien; ${ }^{26}$ und die Logik des Satzgefüges V. 2-4 entspräche der von Joh 1,23. ${ }^{27}$ Die Aufnahme der Wendung ,,in der Wüste“ aus Mk 1,3 in V. 4 kann jedoch nicht als Argument für eine Verknüpfung beider Verse geltend gemacht werden; dieser Stichwortanschluss ist ohne Weiteres auch mit der Annahme syntaktischer Selbständigkeit für V. $4 \mathrm{zu}$ vereinbaren. Eine eindeutige Entscheidung lässt sich demnach bei synchroner Betrachtung der Verse 1-4 nicht fällen.

Im Überblick wird deutlich, dass die syntaktische Analyse von Mk 1,1-4 in drei Hinsichten je zwei Deutungsmöglichkeiten zulässt. Folgende Übersicht veranschaulicht den Befund:

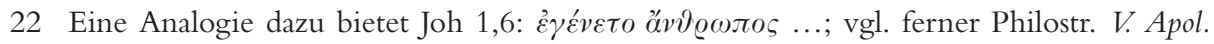

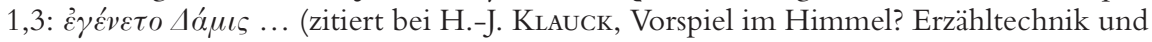
Theologie im Markusprolog [BThSt 32], Neukirchen-Vluyn 1997, 24f.). Der Vorschlag von W. Feneberg, Der Markusprolog. Studien zur Formbestimmung des Evangeliums (StANT 36), München 1974, 186, Mk 1,2f. als Parenthese aufzufassen und deshalb neben dem Zitat - auch V. 4 an V. 1 anzuschließen, hat wenig für sich; da V. 1 dann

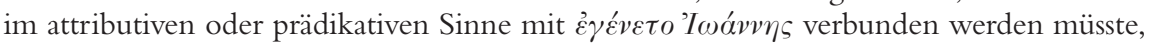

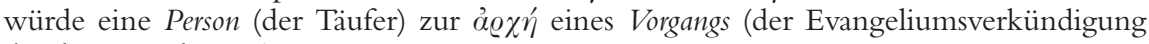
durch Jesus Christus).

23 G. ARNOLD, Mk $1_{1}$ und Eröffnungswendungen in griechischen und lateinischen Schriften, in: ZNW 68 (1977), 123-127, führt deshalb zu Unrecht diverse vollständige Sätze als Parallelen zu Mk 1,1 an.

24 Auch 2Esdr 1,1 (angeführt von D. Dormeyer, Mk 1,1-15 als Prolog des ersten idealbiographischen Evangeliums von Jesus Christus, in: Biblical Interpretation 5 [1997], 181211, hier 183) bietet dazu keine Parallele. Belegt ist die Erweiterung solch einer Wendung durch einen Relativsatz; vgl. Apk 1,1 sowie Hhld 1,1; Spr 1,1.

25 Vgl. J. Marcus, The Way of the Lord. Christological Exegesis of the Old Testament in the Gospel of Mark, Edinburgh 1992, 108f. (zu Mk 9,13).

26 Vgl. Lk 6,31; Joh 5,30b; Röm 1,28; 1 Kor 15,49; 1Joh 2,27d-e.

27 Dort heißt es: „Er (sc. Johannes) sprach: Ich (bin) die ,Stimme eines Rufenden in der Wüste: Macht gerade den Weg des Herrn!', wie Jesaja, der Prophet, gesagt hat.“ 


\begin{tabular}{|c|c|c|}
\hline V.1 & $\begin{array}{c}\text { Ursprung der Evangeliumsverkündigung } \\
\text { Jesu Christi } \rightarrow \text { Mk 1,4-13 o. ä.) }\end{array}$ & $\begin{array}{c}\text { Grundlegung des Evangeliums } \\
\text { von Jesus Christus }(\rightarrow \text { Mk 1,4-16,8) }\end{array}$ \\
\hline V.2 & $\ldots$ Wie & .., wie \\
\hline & $\begin{array}{c}\text { geschrieben ist bei Jesaja, dem Propheten: } \\
\text { Siehe, ich sende meinen Boten vor dir her, der deinen Weg bahnen wird. }\end{array}$ \\
\hline V.3 & $\begin{array}{c}\text { Stimme eines Rufenden } \\
\text { in der Wüste: ,Bereitet }\end{array}$ & $\begin{array}{c}\text { Stimme eines Rufenden: } \\
\text {,In der Wüste bereitet }\end{array}$ \\
\hline V.4 & \multicolumn{2}{|c|}{ den Weg des Herrn, macht gerade seine Pfade!“ } \\
\hline & \multicolumn{2}{|c|}{$\begin{array}{c}\text { Johannes, der Taufende, in der Wüste, und zwar indem er } \\
\text { eine Taufe der Umkehr(, die) zur Vergebung der Sünden (führt,) verkündigte. }\end{array}$} \\
\hline
\end{tabular}

Eine Antwort auf die Frage, inwieweit diese Möglichkeiten plausibel miteinander kombiniert werden können, setzt freilich eine Klärung der Referenzen des Zitats im markinischen Kontext voraus.

\section{Zur referentiellen Einbindung des Zitats Mk 1,2f. in seinen markinischen Kontext}

Von grundlegender Bedeutung für die Deutung des Zitats ist die Identifizierung der in ihm genannten Personen(gruppen). Es enthält insgesamt sechs Bezeichnungen:

- das ,ich“ des Sprechers von Mk 1,2b-c,

- der von diesem Sprecher als „mein Bote“ Vorgestellte (V. 2b, vgl. „der“ in V. 2c),

- das ,du“" des in V. 2b-c Angesprochenen,

- der „Rufende“ in V. 3a,

- die von diesem mit V. 3b-c in der 2. Person Pl. Angesprochenen sowie

- der „Herr" in V. 3b (vgl. ,sein“" in V. 3c).

Nur in einer Hinsicht ist die Sachlage eindeutig: Nach der Einführung des Zitats als eines Prophetenwortes muss das ,,ich“ des Sprechers von V. 2b-c auf Gott gedeutet werden - so, wie es im MkEv auch sonst der Fall ist, wenn sich innerhalb eines Schriftzitats ein ,ich“ zu Wort meldet (7,6f.; 11,17; 12,26.36; 14,27). ${ }^{28}$ Wie sich die übrigen Bezeichnungen zueinander verhalten und worauf sie verweisen, kann nur aus dem Kontext erschlossen werden, in den Markus das Zitat gestellt hat. Der Umfang dieses Kontextes lässt sich allerdings je nach Wahrnehmung

28 Das Psalmwort, das Jesus am Kreuz nachspricht, wird in Mk 15,34 nicht als Schriftzitat eingeführt. 
der Syntax in 1,1-4 verschieden bestimmen. So ergeben sich folgende Interpretationsmöglichkeiten:

a) Sieht man in Mk 1,1 den ,Ursprung der Evangeliumsverkündigung Jesu Christi“" angezeigt, so kann sich der Deutungshorizont des nachfolgenden Zitats (V. 2f.) maximal über die Verse 1-13 (bzw. 1-15) erstrecken; in V. 14f. beginnt Markus ja, die Verkündigung Jesu selbst zu beschreiben. Verknüpft man nun das Zitat syntaktisch mit V. 4, so bietet sich zuerst an, es im Kontext der Verse 4-8, die das Wirken des Täufers schildern, zu interpretieren. Dazu enthalten diese Verse in der Tat einige Anhaltspunkte: Da Johannes ,,in der Wüste“ als „Verkündiger“ auftritt (V. 4), als solcher das ganze judäische Land und alle Jerusalemer erreicht (V. 5) und diese Leute noch einmal direkt anspricht (V. 8), wird man V. 3a auf das „Rufen“ des Täufers ,,in der Wüste“ deuten und in V. 3b-c seine Botschaft an jene - wie in V. 8 in der 2. Person Pl. angesprochenen - Leute in Worte gefasst sehen. Andererseits weist V. 7 mit der Ankündigung: „Es kommt der, der stärker ist als ich, nach mir ...", auf die Sendung eines „Boten vor dir her“ (V. 2b) zurück. Demgemäß erscheint V. 2 als Gotteswort, das dem „Stärkeren“ die Sendung des Täufers als eines Wegbahners zusagt, V. 3 sodann als prophetische Darstellung der Verkündigung des Täufers; in V. 4-6 und V. 7f. beschreibt Markus daraufhin in umgekehrter Folge - die Erfüllung dieser zweiteiligen Weissagung durch das Wirken des Johannes. Dabei ist jener „Stärkere“ von V. 1 her auf Jesus Christus zu deuten, dessen eigene Evangeliumspredigt ja vorbereitet werden soll. Den Weg Jesu bahnt der Täufer demnach auf doppelte Weise. Zunächst tritt er ähnlich wie später Jesus selbst als ,,Verkündiger“ auf: ${ }^{29}$ Ruft dieser angesichts der nahe gekommenen Gottesherrschaft zur Umkehr (V. 15), so verkündet Johannes eine „,Taufe der Umkehr“ (V. 4). Sodann sagt er das Auftreten Jesu an und vergleicht sein eigenes „Taufen im Wasser“ mit dem „Taufen im Heiligen Geist“, das Jesus an den Menschen vollziehen werde. ${ }^{30}$ Die Rede vom „Bahnen“ des Weges zielt, so verstanden, auf das Wirken des Täufers als des Vorläufers und Heroldes Jesu. Dann aber muss die Aufforderung in V. 3, ,den Weg des Herrn“ zu ,,bereiten“, etwas Anderes intendieren als V. 2c; ihre Adressaten, die Bewohner Judäas und Jerusalems, agieren ja weder als Vorläufer noch als Herolde Jesu. Vielmehr reagieren sie auf Johannes' Verkündigung einer ,Taufe der Umkehr“, indem sie ihre Sünden bekennen und sich im Jordan taufen lassen (V. 5). Es liegt deshalb nahe, V. 3b-c als Aufruf zur Vorbereitung auf die Begegnung mit Gott selbst zu deuten - eine Begegnung, die Jesus dann mit seiner Verkündigung der nahe gekommenen Gottesherrschaft in Aussicht stellt. ${ }^{31}$

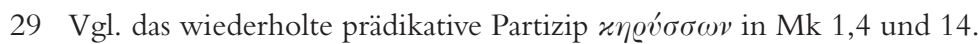

30 Was mit Letzterem gemeint ist, bleibt im Rahmen von Mk 1,1-8 offen.

31 Dazu passt, dass xv́@ı๐ ohne Artikel in markinischen Schriftzitaten sonst stets auf Gott

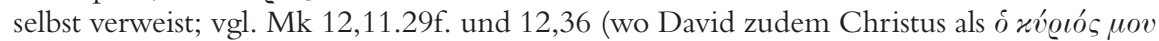
bezeichnet), ferner die Anspielung in 11,9. - Die skizzierte Deutung wird detailliert entfaltet von T. R. Hatina, In Search of a Context. The Function of Scripture in Mark's Narrative (JSNT.S 232), Sheffield 2002, 163-183. Hatina betont dabei die ethische Dimension der in Mk 1,3 geforderten ,preparation“ (169.182f.). 
So einleuchtend diese Deutung des Zitats ist, sie weckt doch an zwei Punkten Bedenken: Ist es wahrscheinlich, dass gerade die Identifikation des in Mk 1,2b-c Angesprochenen mit Jesus Christus nur indirekt, durch die Rede vom „Stärkeren“ in V. 7, gestützt wird? Und ist es plausibel, die einander so ähnlichen und eben dadurch die Einheit des Zitats gewährleistenden Aussagen V. 2c und V. 3b auf verschiedene Personen und Vollzüge zu deuten?

b) Beide Anstöße lassen sich ausräumen, wenn man - unter Beibehaltung der eingangs in Absatz a) genannten syntaktischen Entscheidungen zu Mk 1,1.4 einen weiteren Deutungshorizont für V. 2f. annimmt und die Verse 9-11 in ihn einbezieht. Da V. 11 erzählt, wie Gott selbst Jesus in der 2. Person Sing. anspricht und ihn zu „meinem Sohn“ ernennt, erhält das Verständnis von V. 2b-c als einem an Jesus gerichteten Gotteswort eine nachträgliche Bestätigung. ${ }^{32}$ Zudem wird jener Zuspruch in V. 11 einer „Stimme aus den Himmeln“ zugeschrieben, sodass es nahe liegt, auch in V. 3 die „Stimme“ Gottes zu hören; dann ergeht dort, anhebend mit „In der Wüste bereitet ...", die Berufung des Täufers, ${ }^{33}$ und sein Auftrag besteht darin, den „Weg des Herrn“ zu ,,bereiten“ und eben damit gemäß V. 2c - den „Weg“" Jesu zu „,bahnen““. ${ }^{34}$ Man wird daraus nicht einfach folgern können, dass Jesus mit dem xv́øı son V. 3 identisch ist; ${ }^{35}$ vielmehr dürfte in der Kombination von V. $2 \mathrm{~b}-\mathrm{c}$ mit V. 3 die Überzeugung zum Ausdruck kommen, dass im Wirken Jesu Gott selbst am Werk ist ${ }^{36}$ - und dass deshalb der „Weg des Herrn“ kein anderer ist als der „Weg“ Jesu. Darüber hinaus wird im Kontext der Verse 4-11 der Sinn der Rede von der „Bereitung“ jenes Weges vertieft: Da sich Jesus der Taufe durch Johannes unterzieht und daraufhin mit dem Geist begabt wird (V. 9f.), erscheint der Täufer auch als Mittler der Bevollmächtigung Jesu. Damit klärt sich zugleich der Sachgehalt der Aussage von V. 8b: Weil der Heilige Geist auf Jesus ruht, werden Menschen in der Begegnung mit Jesus in den Machtbereich dieses Geistes ,eingetaucht“. Vor diesem Hintergrund lässt sich dann auch der Gebrauch des Christustitels in V. 1 erklären: Wird Jesus nämlich nach 8,(27-)29 infolge seines öffentlichen, durch Wundertaten geprägten Wirkens als „der Christus“ erkannt und bekannt ${ }^{37}$ - eines Wirkens, das nach 3,(22-)29f. in der Kraft des Heiligen Geistes erfolgt -, so bezeichnet „Christus“ (1,1) denjenigen,

32 Dass Gott schon in der Schrift zu Christus spricht, findet seine Entsprechung in Mk 12,36.

33 Auf die gleiche Weise wird dasselbe Schriftwort in Lk 3,2b-4 gedeutet; s. u. Absatz 4.

34 Mk 1,3 bezeugt also letztlich den faktischen Vollzug der Berufung des Täufers. In ähnlicher Weise verwendet Markus ein Schriftzitat auch in 12,10f.; vgl. ferner Röm 2,24; 10,15.16 und dazu Wilk, Bedeutung des Jesajabuches, 73-79.

35 Dieser Annahme (vgl. z. B. W. Eckey, Das Markusevangelium. Orientierung am Weg Jesu. Ein Kommentar, Neukirchen-Vluyn 1998, 57) steht der in Anm. 31 angeführte Befund entgegen.

36 Diese Überzeugung wird im MkEv auch andernorts erkennbar; vgl. v. a. Mk 5,19.20 und

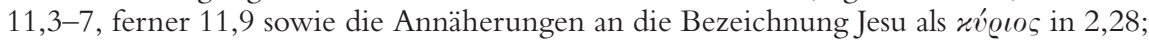
7,$28 ; 12,37$ und 13,35 .

37 Vgl. dazu R. Weber, Christologie und „Messiasgeheimnis“: ihr Zusammenhang und Stellenwert in den Darstellungsintentionen des Markus, in: EvTh 43 (1983), 108-125, hier 119. 
der von Gott zum Träger dieses Geistes gemacht worden ist (V. 10). So gesehen, erweisen sich die in V. 4-11 geschilderten Vorgänge als Erfüllung der in V. 2f. zitierten Prophetie: Der Täufer bahnt, wie in V. 2 angekündigt, den Weg Jesu und bereitet, wie in V. 3 angeordnet, den Weg des Herrn, indem er zunächst - mit seiner Umkehrpredigt - als Vorläufer Jesu, sodann als Herold seines Kommens und Wirkens und schließlich als Mittler seiner Bevollmächtigung zum Repräsentanten Gottes auftritt.

Diese Interpretation löst freilich ebenfalls Rückfragen aus: Darf man die pluralischen Imperative in Mk 1,3 auf den Täufer als Einzelperson beziehen $?^{38}$ Und können die Verse 9-11 über den narrativen Neueinsatz in V. 9 hinweg - von dem an Jesus zur Hauptfigur der Erzählung wird - ohne Weiteres mit 1,4-8 verbunden und dem Zitat in V. 2f. zugeordnet werden?

c) Solche Rückfragen lassen sich vermeiden, wenn das Zitat syntaktisch mit V. 1 verknüpft und dementsprechend im Zusammenhang mit den Versen 4-13 ausgelegt wird. In V. 13 greift Markus ja die Wendung ,,in der Wüste“ noch ein-

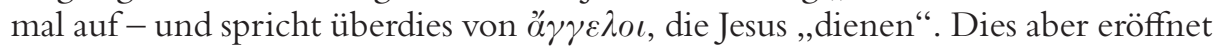
die Möglichkeit, V. 3 sowohl an den Täufer als auch an Jesus gerichtet zu verstehen. Der Auftrag, in der Wüste ,den Weg des Herrn zu bereiten“, richtet sich dann an beide in V. 2 genannten Personen, Gottes ă $\gamma \gamma \varepsilon \lambda o \varsigma$ und den mit „du“ Angesprochenen; und indem diese je auf ihre Weise den Auftrag erfüllen, schaffen sie die Basis für die Verkündigung des Evangeliums durch Jesus Christus (V. 1). Dabei wirkt der Täufer als Vorläufer und Herold Jesu (V. 4-8), dieser selbst aber durch seinen Gang zur Taufe und seine anschließende Bewährung angesichts der Versuchung durch den Satan (V. 9-13) daran mit, ,,in der Wüste“ jene Basis zu legen. Die Rede vom ,Weg des Herrn“ aber weist in diesem Kontext gemäß V. 15 darauf, dass die Herrschaft Gottes im Wirken Jesu bei denen, die seiner Verkündigung glauben, gleichsam ,,ankommt“, d. h. anfänglich präsent wird - so, wie es die beiden Gleichnisse von der Gottesherrschaft in 4,26-29.30-32 metaphorisch darstellen.

Auch diese Deutung weist jedoch Unschärfen auf. Ist es einleuchtend, den einen Auftrag von V. 3 bei Johannes und Jesus auf so unterschiedliche Weise erfüllt zu sehen? Steht diese Auffassung nicht in Spannung zu dem Sachverhalt, dass V. 15 zufolge auch Jesus, in Analogie zum Täufer, als Umkehrprediger auftritt - und dass schon V. 8 die jeweiligen Tätigkeiten beider miteinander vergleicht?

d) In der Tat lässt das MkEv im weiteren Verlauf der Erzählung noch eine ganze Reihe von Parallelen zwischen beiden Figuren erkennen:

Beide sind von Gott „gesandt“ $(1,2 / 9,37 ; 12,6)$, haben also ihre Autorität ,,vom Himmel“ (11,30-32 / 1,11; vgl. 9,7); beide sprechen von der „,Vergebung der Sünden“ (1,4 / 2,5-10, vgl. $3,28 ; 4,12 ; 11,25)$; beide erhalten großen Zulauf aus Judäa und Jerusalem (1,5 / 3,7f.); beide haben ,Jünger“ $(2,18 ; 6,29 / 2,15 f .18 .23$ u. v. ö.); beide werden (Jesus freilich unzutreffender-

38 Vgl. dagegen 1QS 8,12-16, wo das Zitat ebenfalls als Wort der Berufung zu einer besonderen Aufgabe gedeutet, als solches aber auf eine Gemeinschaft angewendet worden ist. 
weise) mit Elija identifiziert $(9,11-13 / 6,15 ; 8,28)^{39}$ und vom Volk als „Prophet“ bezeichnet $(11,32 / 6,15 ; 8,28)$; bei beiden wird die jeweils endgültige Identifikation als eschatologische Gestalt mit diesbezüglichen Aussagen der „Schriftgelehrten“ kontrastiert (9,11/12,35); beide ziehen sich (in je anderem Sachzusammenhang) ${ }^{40}$ mit ihrer Interpretation der Thora die Todfeindschaft (je anderer) jüdischer Autoritäten zu (6,18f. / 2,23-3,6, ${ }^{41}$ vgl. 11,18; 12,12; 14,1); beide werden ,,ausgeliefert“ (1,14 / 3,19; 9,31; 10,33; 14,10f.18.21.41f.44; 15,1.15); in beiden Fällen wird die Tötungsabsicht zunächst durch „Furcht“ gebremst (6,19f., vgl. 11,32 / 11,18; 12,12), da beide ,gern gehört" werden $(6,20$ / 12,37); beide werden auf eine willkürliche Initiative ihrer Todfeinde hin (6,21-25/14,53-64; 15,1.10f.) vom zuständigen Machthaber, obwohl für unschuldig befunden $(6,20 / 15,14)$, zum Tode verurteilt und dann von dessen Bediensteten hingerichtet $(6,27$ / 15,15.20.24); beider Geschick wird als schriftgemäß gekennzeichnet (9,13 / 9,12; 14,21, vgl. 14,27.49); in beiden Fällen „legen“ Anhänger „den Leichnam“ in ein „Grab“ (6,29 / 15,43-46); beiden (Johannes allerdings irrtümlicherweise) wird nachgesagt, sie seien ,auferweckt" worden (6,14.16/16,6, vgl. 14,28 [im Munde Jesu]). ${ }^{42}$

Die Ähnlichkeit geht so weit, dass im Volk die Meinung kursiert, Jesus sei niemand anders als (der von den Toten auferweckte) Johannes der Täufer $(6,14 ; 8,28)$. Gewiss stellt Johannes selbst von Anfang an klar, dass Jesus als „der Stärkere“ ihm weit überlegen ist $(1,7)$; dementsprechend übertrifft dieser den Täufer an fast allen genannten Berührungspunkten. Johannes ist eben „nur“ der Vorläufer Jesu. Doch gerade in dieser Hinsicht besteht noch eine Entsprechung zwischen beiden: Wie Johannes ,,vor“ Jesus ,her“ gesandt wird (1,2), so geht Jesus seinen Jüngern „voraus" - nach Jerusalem als dem Ort seines Leidens, Sterbens und Auferstehens $(10,32)$ sowie nach Galiläa als dem Ort, wo sie ihn nach seiner Auferstehung erneut sehen werden $(14,28 ; 16,7)$; und wie Johannes ankündigt, jener Stärkere werde ,hinter mir her" kommen $(1,7)$, so ruft Jesus Menschen auf, ,hinter mir her" zu folgen (1,17; 8,34, vgl. 1,20; 8,33). Damit aber eröffnet sich die Möglichkeit, das Schriftzitat in 1,2 auf das Verhältnis zwischen Jesus und seinen Jüngern zu deuten; es stellt, so verstanden, Jesus als den „Boten“ Gottes dar, der seinen Nachfolgern den Weg bahnt. ${ }^{43}$ Mit ,du“ angesprochen ist dabei, wie in anderen markinischen Schriftzitaten, das Volk Gottes (vgl. 12,29f.) bzw. jedes seiner Mitglieder (vgl. 7,10; 10,19; 12,31) - das ja in 1,5 auch umgehend in Erscheinung

39 Die Identifikation des Täufers mit Elija wird zwar in Mk 9,11-13 nicht explizit durchgeführt; sie ergibt sich aber zweifelsfrei aus den Übereinstimmungen zwischen 9,11 und 1,2 im Rückgriff auf Mal 3 (dazu s. u. Abschnitt 6.d), zwischen Mk 9,12 und 1,5 in der Darstellung des umfassenden Erfolgs sowie zwischen 9,13 und 6,19-25 in der Rede vom „,willentlich“ herbeiführten Geschick dieser Gestalt. Vgl. ferner die deutliche Anspielung auf 2Kön [4Regn] 1,8 in Mk 1,6 (auch dazu s. u. Abschnitt 6.d) und zum Ganzen M. Öhler, Elia im Neuen Testament. Untersuchungen zur Bedeutung des alttestamentlichen Propheten im frühen Christentum (BZNW 88), Berlin/New York 1997, 38-47.

40 Im radikalen Verständnis des Ehebruch-Verbots stimmt Jesus (Mk 10,1-12) freilich mit Johannes (6,18) überein; dazu (und zu der in 10,1f. implizit hergestellten Verbindung zum Geschick des Täufers) vgl. F. Wilk, Ein für alle Mal!? Zur Verbindlichkeit der Ehe im Neuen Testament, in: LVK-Forum (2/2007), 34-44, hier 34-36.

41 Diese Parallele unterstreicht Markus, indem er Pharisäer wiederholt mit Herodes und seinen Anhängern assoziiert (Mk 3,6; 8,15; 12,13).

42 In Mk 8,31; 9,9.31; 10,34 kündigt Jesus selbst sein „Auferstehen“ an.

43 Vgl. dazu Tolbert, Sowing the Gospel, 241-247. 
tritt. Gestützt wird diese Deutung durch den Befund, dass der Begriff $\tilde{\eta}$ ó $\delta$ '́ im MkEv eine zentrale Rolle spielt und in 8,27; 9,33f.; 10,32.52 den Weg bezeichnet, auf dem die Jünger Jesus nach Jerusalem folgen. ${ }^{44}$ In 1,3 dürfte dann der göttliche Auftrag zur Sprache kommen, das endzeitliche Kommen Gottes zu verkündigen und demgemäß das Gottesvolk zur Umkehr zu rufen - ein Auftrag, den zuerst der Täufer als Vorläufer Jesu, sodann Jesus selbst wahrnimmt. ${ }^{45}$ In diesem Sinne lässt sich das Schriftzitat gut an die Kopfzeile V. 1 anschließen - sofern man dort 'I von Christus ( $\varepsilon \dot{v} \alpha \gamma \gamma \varepsilon \lambda i ́ o v)$ vollzieht sich in einem Geschehen, das der Ankündigung der Schrift entspricht: Gott sendet seinen Boten ( $\left.\alpha_{\gamma} \gamma \varepsilon \dot{\varepsilon} \boldsymbol{\lambda}\right)$ ) Jesus, um dem Gottesvolk den Weg (in die Nachfolge und damit in die Gottesherrschaft bzw. ins ewige Leben $)^{46}$ zu bahnen, und weist deshalb sowohl den Täufer als auch Jesus selbst an, das Volk auf die eschatologische Begegnung mit Gott vorzubereiten; und von diesem Geschehen, das sich im Wirken und Geschick Jesu (und seines Vorläufers) vollzieht, erzählt das MkEv. So gelesen, dienen die Verse 1-3 als Prolog zur ganzen Jesuserzählung des Markus.

Doch diese Auslegung ist ihrerseits nicht frei von Problemen: Kann man den $\not ̈ \gamma \gamma \varepsilon \lambda o \varsigma$ in Mk 1,2 auf Jesus deuten, wenn dieser doch in 1,13 und 8,38; 13,27.32 von den $\ddot{\alpha} \gamma \gamma \varepsilon \lambda_{0 \iota}$ unterschieden und ihnen erkennbar übergeordnet wird? Und ist es plausibel, ,in der Wüste“ als Angabe des Ortes der Berufung (des Täufers und) Jesu zu verstehen, ${ }^{47}$ wenn Markus dort explizit nur das Auftreten des Täufers und die Versuchung Jesu lokalisiert?

e) Angesichts dieser Probleme kommt noch eine andere Deutungsmöglich-

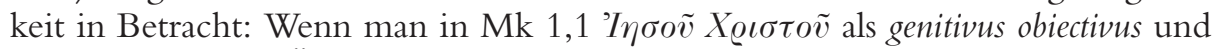
V. 1 daraufhin als Überschrift zum ganzen Buch auffasst, kann man V. 2f. auch syntaktisch mit V. 4 und der Sache nach mit V. 4-6 verknüpfen. Dann berichtet Markus, wie das Wirken des Johannes seiner Sendung, dem Gottesvolk den Weg zu bereiten (V. 2), und der Prophetie, die sein Rufen in der Wüste weissagt (V. 3), entspricht: Er tritt als Prediger und Täufer in der Wüste auf und veranlasst alle Judäer sowie Jerusalemer, ihm dorthin zu folgen und sich mit ihrer Taufe (als Auftakt ihrer Umkehr) auf die Begegnung mit Gott vorzubereiten.

44 Vgl. ferner die Hinweise auf den Weg der Jünger (Mk 2,23; 6,8) sowie auf den Weg als Ort, auf dem Menschen Jesus begegnen $(10,17.46 ; 11,8)$.

45 Vgl. dazu das Zugeständnis einiger Pharisäer und Herodianer, dass Jesus „,den Weg Gottes wahrhaftig lehre“, in Mk 12,14. - Auf das „Rufen“"Jesu lässt sich 1,3 kaum deuten, da seine Verkündigung dem MkEv zufolge weder auf ein Agieren der Hörer ,in der Wüste“ zielt

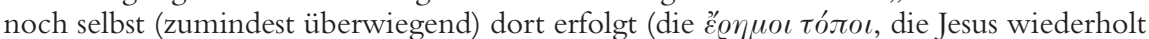
aufsucht [vgl. 1,35.45; 6,31f.], dienen ihm gerade als Orte des Rückzugs vor dem Zulauf, den sein Wirken auslöst; nur im Vorfeld der Speisungswunder werden sie auch zu Orten der Lehre [6,32-34, vgl. 8,2-4]).

46 Vgl. die Wendungen ,,in die Gottesherrschaft ..." bzw. „ins Leben eingehen“ in Mk 9,47; 10,15.23-25 bzw. 9,43.45.

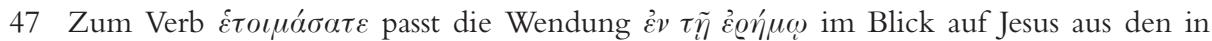
Anm. 45 genannten Gründen nicht. 
Allerdings erheben sich auch hier Bedenken: Ist es wahrscheinlich, dass das erste und derart exponierte Schriftzitat im MkEv keinen Bezug zu Person und Wirken Jesu Christi aufweist? Muss man also - nach dem als Buchüberschrift gedeuteten Vers Mk 1,1 - V. 2f. doch (f) mit V. 4-8 oder (g) mit V. 4-11 verbinden? Dann aber stellen sich die zu den Absätzen a) und b) aufgeworfenen Fragen erneut.

Insgesamt ergibt sich somit ein Nebeneinander von sieben Deutungsmöglichkeiten:

\begin{tabular}{|c|c|c|c|c|c|}
\hline Deutung & $a \| f$ & $\mathrm{~b} \| \mathrm{g}$ & $\mathrm{c}$ & $\mathrm{d}$ & $\mathrm{e}$ \\
\hline V. 1 & \multicolumn{2}{|c|}{$\begin{array}{c}\text { Ursprung || Grundlegung } \\
\text { des Evangeliums } \\
\text { Jesu || von Christus: }\end{array}$} & $\begin{array}{l}\text { Ursprung } \\
\text { des Evangeliums } \\
\text { Jesu, }\end{array}$ & $\begin{array}{l}\text { Grundlegung } \\
\text { des Evangeliums } \\
\text { von Christus, }\end{array}$ & $\begin{array}{l}\text { Grundlegung } \\
\text { des Evangeliums } \\
\text { von Christus: }\end{array}$ \\
\hline \multirow[t]{5}{*}{ V. 2} & \multicolumn{2}{|c|}{ Wie die Schrift sagt: } & \multicolumn{2}{|c|}{ wie die Schrift sagt: } & Wie die Schrift sagt: \\
\hline & \multicolumn{5}{|c|}{ Gott sendet } \\
\hline & \multicolumn{2}{|c|}{ den Täufer } & den Täufer & Jesus Christus & den Täufer \\
\hline & \multicolumn{5}{|c|}{ als Wegbahner } \\
\hline & \multicolumn{2}{|c|}{ vor Christus her; } & vor Christus her; & vor dem Volk her; & vor dem Volk her; \\
\hline \multirow[t]{6}{*}{ V. 3} & \multirow{2}{*}{$\begin{array}{l}\text { Johannes ruft } \\
\text { in der Wüste: }\end{array}$} & Gott beruft: & Gott beruft: & \multirow{2}{*}{$\begin{array}{l}\text { Gott beruft in } \\
\text { der Wüste: }\end{array}$} & \multirow{2}{*}{$\begin{array}{l}\text { Johannes ruft } \\
\text { in der Wüste: }\end{array}$} \\
\hline & & \multirow{2}{*}{$\begin{array}{l}\text { In der Wüste } \\
\text { soll Johannes }\end{array}$} & \multirow{2}{*}{$\begin{array}{l}\text { In der Wüste sollen } \\
\text { Johannes und Jesus }\end{array}$} & & \\
\hline & Das Volk soll & & & $\begin{array}{l}\text { (Johannes und) } \\
\text { Jesus soll(en) }\end{array}$ & Das Volk soll \\
\hline & \multicolumn{5}{|c|}{ den Weg bereiten, auf dem } \\
\hline & es & (in Jesus) & (im Wirken Jesu) & Jesu Nachfolger & es \\
\hline & $\begin{array}{l}\text { Gott begeg- } \\
\text { net, }\end{array}$ & $\begin{array}{l}\text { Gott zur } \\
\text { Erscheinung } \\
\text { kommt. }\end{array}$ & $\begin{array}{l}\text { Gott zur Herrschaft } \\
\text { kommt. }\end{array}$ & Gott begegnen. & Gott begegnet, \\
\hline \multirow[t]{3}{*}{ V. 4} & $\begin{array}{l}\text { V. 4-8: } \\
\text {...so tritt Jo- } \\
\text { hannes auf: }\end{array}$ & $\begin{array}{l}\text { V. 4-11: } \\
\text { ‥so tritt } \\
\text { Johannes auf: }\end{array}$ & $\begin{array}{l}\text { V. 4-13: } \\
\text { Demgemäß agieren } \\
\text { Johannes } \\
\text { und Jesus: } \\
\end{array}$ & \multirow{3}{*}{$\begin{array}{l}\text { 1,4-16,8: } \\
\text { Demgemäß er- } \\
\text { folgt (Johannes') } \\
\text { und Jesu } \\
\text { Wirken } \\
\text { und Geschick }\end{array}$} & $\begin{array}{l}\text { V. 4-6: } \\
\ldots, \text { so tritt Johannes } \\
\text { auf }\end{array}$ \\
\hline & \multirow{2}{*}{$\begin{array}{l}\text { als Vorläufer } \\
\text { und Herold } \\
\text { Jesu }\end{array}$} & \multirow{2}{*}{$\begin{array}{l}\text { als Vorläufer, } \\
\text { Herold und } \\
\text { Mittler der } \\
\text { Bevollmäch- } \\
\text { tigung Jesu }\end{array}$} & $\begin{array}{l}\text { Johannes als Vorläu- } \\
\text { fer und Herold Jesu, }\end{array}$ & & \multirow{2}{*}{$\begin{array}{l}\text { als Täufer und Predi- } \\
\text { ger der Umkehr } \\
\text { für ganz Judäa und } \\
\text { Jerusalem }\end{array}$} \\
\hline & & & $\begin{array}{l}\text { Jesus durch seine } \\
\text { Taufe und Versu- } \\
\text { chung }\end{array}$ & & \\
\hline
\end{tabular}

Jede dieser Deutungsmöglichkeiten hat ihre eigenen Vorzüge und Probleme. Welche von ihnen am ehesten der Intention des MkEv entspricht, lässt sich offenbar allein durch dessen synchrone Analyse nicht klären. Hilft ein synoptischer Vergleich weiter?

\section{Mk 1,1-4 im Lichte seiner synoptischen Parallelen}

Die Parallelen zu Mk 1,1-4 finden sich bei den anderen Synoptikern an drei verschiedenen Stellen. Was zunächst V. 1 betrifft, so beginnt das MtEv mit der - 


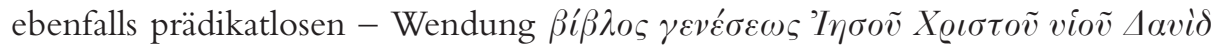

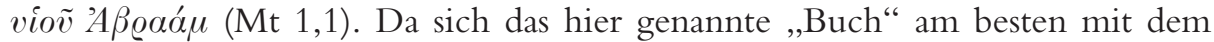
Stammbaum in V. 2-17 identifizieren lässt, ${ }^{48}$ steht zu vermuten, dass Matthäus Mk 1,1 als Kopfzeile zum Auftakt der markinischen Jesuserzählung (in den Versen 2-13) aufgefasst und deshalb seinen eigenen „Vorspann“ mit einer formal weitgehend analog gestalteten Überschrift versehen hat. Diese Vermutung lässt sich durch zwei weitere Sachverhalte untermauern: „Christus“ heißt Jesus im MtEv deshalb, weil ihn sein Leben und Auftreten - von der Geburt $(1,18 ; 2,4)$ über seine Wunder $(11,2)$ und zumal seine Lehre $(23,10)$ bis hin zu seiner Passion $(26,63.68 ; 27,17.22)$ - als denjenigen erweist, in dem sich alle Heilszusagen Gottes an Israel erfüllen; ${ }^{49}$ dem Ausdruck „Evangelium Jesu Christi““ aus Mk 1,1 kommt Matthäus dort am nächsten, wo er "Jesus“ innerhalb einer summarischen Darstellung seines Wirkens als „Verkünder des Evangeliums vom Reich“ bezeichnet (Mt 9,35). Lukas hingegen beginnt sein Jesusbuch mit einem das ganze Werk eröffnenden Prolog (Lk

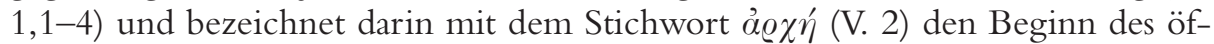
fentlichen Wirkens Jesu im Anschluss an die Tätigkeit des Täufers. ${ }^{50}$ Dabei erstreckt sich dieses Wirken nach lukanischer Darstellung bis zur Himmelfahrt - und findet dann im Zeugendienst der Jünger seine Fortführung. ${ }^{51}$ erst durch diesen kommt ja das Jesus-Geschehen für die, denen er zuteil wird, zur Erfüllung (V. 1).$^{52}$ So liegt die Annahme nahe, dass Lukas Mk 1,1 für den Titel der ganzen Schrift gehalten und als solchen durch seinen Prolog ersetzt hat. Dafür spricht auch die Tatsache, dass er die Christuswürde Jesu (Lk 2,10) in dessen Durchgang durchs Leiden in die Herrlichkeit vollendet sieht $(24,26)$; denn erst als der zur Rechten Gottes Erhöhte (20,41-44) kann Jesus seine Königsherrschaft (1,32f.; 19,38; 23,2) ausüben, indem er sich an denen, die ihm vertrauen (23,39-43) und sich durch die Zeugen des Heilsgeschehens zur Umkehr rufen lassen (24,46-48), als Christus und Retter $(2,10)$ erweist. ${ }^{53}$ Demgemäß hat der markinische Begriff $\varepsilon \dot{v} \alpha \gamma \gamma \gamma^{\prime} \lambda \iota{ }^{\prime}{ }^{\prime} I \eta \sigma o \tilde{v}$

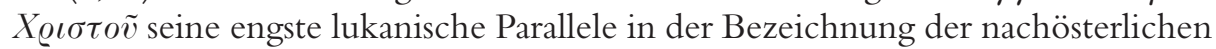

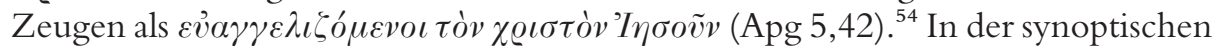
Wirkungsgeschichte sind demnach beide oben diskutierten Deutungsmöglichkeiten zu Mk 1,1 bezeugt.

Ein größeres $\mathrm{Maß}$ an Übereinstimmung zwischen Matthäus und Lukas besteht im Hinblick auf ihre jeweilige Rezeption von Mk 1,2-4. Was zunächst V. 2a.3.4 angeht, so sind die entsprechenden Elemente sowohl in Mt 3,1-3 als auch in Lk 3,1-6 miteinander verknüpft. Offenbar haben beide Evangelisten Mk 1,2-4

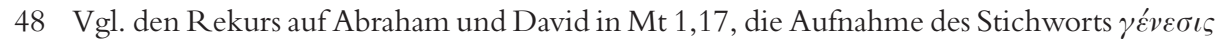
in V. 18, die Analogie zu Gen 5,1 und zum Ganzen WiLk, Jesus und die Völker, 83.

49 Vgl. WiLk, Jesus und die Völker, 135.

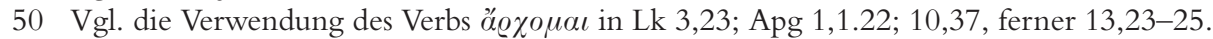

51 Vgl. Lk 24,50f.47-49; Apg 1,2-9.22; 10,38-42, ferner 2,22-36; 3,13-15; 13,23-31.

52 Vgl. dazu Wilk, Jesus und die Völker, $154 f$.

53 Vgl. WiLk, Jesus und die Völker, 175-177.194-197.

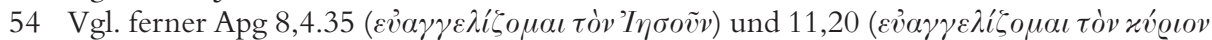
'I $\eta \sigma o \tilde{v} v)$. 
als syntaktische Einheit angesehen; denn beide haben - anders als Markus - das Schriftzitat mit der auf den Propheten Jesaja verweisenden Zitationsformel an eine Notiz zur Verkündigungstätigkeit des Johannes angeschlossen. Dabei ist die Wen-

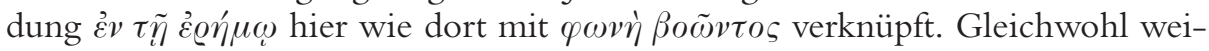
chen die gebotenen Deutungen des Jesajazitats beträchtlich voneinander $a b$.

Lukas erzählt in Lk 3,1-3 zunächst davon, wie Johannes in der Wüste - wo er sich 1,80 zufolge seit längerem aufhält - berufen wird und daraufhin als Umkehrprediger und Täufer am Jordan auftritt. Das folgende, gegenüber Mk 1,3 erweiterte Jesajazitat führt seine Berufung sodann auf eine biblische Prophetie zurück; ${ }^{55}$ und an diesem dreigliedrigen Zitat (Lk 3,4.5.6) orientiert sich die folgende, ihrerseits dreiteilige Darstellung der Verkündigung des Täufers (V. 7-9.10-14.15-17). Er erfüllt also den ihm durch eine göttliche „Stimme“ übermittelten Auftrag, „den Weg des Herrn zu bereiten“ (V. 4), indem er das Volk auf „den kommenden Zorn" hinweist und aufruft, auf die Taufe Taten der Umkehr folgen zu lassen (V. 7f.). ${ }^{56}$ So entspricht die lukanische Darstellung den Ankündigungen aus der Vorgeschichte, Johannes werde als „Prophet des Höchsten ... seine [sc. des Herrn] Wege bereiten“, indem er ,seinem Volk die Erkenntnis“ vermittele, dass es „Rettung ... durch die Vergebung der Sünden“ erfährt (1,76f.), und ,viele Israeliten zum Herrn, ihrem Gott, kehre“ sowie zu einem gerechten Umgang miteinander (1,16f.). Matthäus hingegen stellt Johannes von Anfang an als „Verkündiger in der Wüste Judäas" dar (Mt 3,1f.). Als solchen identifiziert er ihn mit der vom Propheten Jesaja angekündigten „Stimme eines Rufenden in der Wüste“ (V. 3). Die in dieser Prophetie enthaltene Botschaft „Bereitet den Weg des Herrn ..." richtet der Täufer also dadurch aus, dass er Israel angesichts der Nähe des Himmelreichs zur Umkehr ruft (V. 2). ${ }^{57}$

So ist die synoptische Wirkungsgeschichte von Mk 1,2a.3.4 durch eine einheitliche Wahrnehmung der Syntax dieser Verse gekennzeichnet; zugleich aber spiegelt sie im Blick auf V. 3 die Mehrdeutigkeit des markinischen Textes wider.

Die Einheitlichkeit hinsichtlich der Syntax hängt freilich auch damit zusammen, dass Matthäus und Lukas das in Mk 1,2b-c zitierte Schriftwort in ganz anderem Zusammenhang, nämlich im Rahmen einer Sammlung von Worten Jesu über den Täufer (Mt 11,7-19 // Lk 7,24-35) überliefern. Dabei schließt dieses Zitat in Mt 11,10 wie in Lk 7,27 mit der in Mk 1,2 ursprünglich wohl nicht enthaltenen ${ }^{58}$ Wendung ع́ unabhängig voneinander a) das Zitat aus Mk 1,2f. entflochten, b) seinen ersten Teil gleichlautend ergänzt und c) diesen dann auf gleiche Weise in ihre Jesuserzählungen eingefügt haben. Daher dürfte ihnen das V. 2b-c entsprechende Zitat im Kontext der o. g. Jesusworte überliefert worden sein. In diesem Kontext aber verweist es seiner Einleitung (,Dieser ist es, über den geschrieben ist ...") gemäß eindeutig auf die Sendung des Täufers durch Gott. Wessen Weg durch ihn gebahnt werden soll, wird nicht ganz so deutlich; vieles spricht allerdings dafür, dass vom Weg des Gottesvolkes die Rede ist.

55 Vgl. die Entsprechung zwischen Lk 3,2b und V. 4b.

56 Vgl. Wilk, Jesus und die Völker, 181f.

57 Im Folgenden charakterisiert der Evangelist Johannes als Wüstenbewohner (Mt 3,4), schildert seinen großen Erfolg (V. 5f.) und unterstreicht auf diese Weise die Identifikation mit

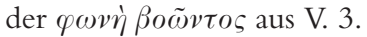

58 Siehe u. Anm. 95. 
Schon der engere Kontext Mt 11,7-11 // Lk 7,24-28, dem zufolge Jesus „die Volksmassen“ auf ihre unzureichende Wahrnehmung des Johannes anspricht, ihn dabei aber „dem Kleinsten im Reich der Himmel / Reich Gottes" nachordnet, legt es nahe, in der 2. Person Sing. das Gottesvolk angesprochen zu sehen; der Täufer ist deshalb „mehr als ein Prophet“, weil er den

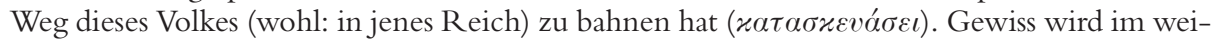
teren Kontext die Ankündigung des „Kommenden“ durch den Täufer (vgl. Mt 3,11f. // Lk 3,16f.) in Erinnerung gerufen (Mt 11,3 // Lk 7,19[-20]) und dessen Auftreten mit dem des Menschensohns verglichen (Mt 11,18f. // Lk 7,33-35), sodass Johannes Jesus zeitlich vor- und sachlich zugeordnet wird. Als „Vorbereitung des Weges Jesu“ ist sein Wirken damit aber nicht gekennzeichnet. Solange man das Zitat Mt 11,10 // Lk 7,27 in diesem Sinne versteht, „bleibt“ es im Textzusammenhang „eine Art Fremdkörper“. ${ }^{59}$ Demgegenüber lässt sich die Deutung auf den Weg des Volkes auch im Gesamtzusammenhang des MtEv sowie des lukanischen Doppelwerkes plausibel machen: Lukas präsentiert Johannes ja in Lk 1,16f.76 als „Propheten“, der vor ,dem Herrn hergeht“, indem er „viele Israeliten zum Herrn, ihrem Gott, kehrt“ und so „dem Herrn ein zugerüstetes Volk ( $\lambda \alpha o ̀ v ~ \varkappa \alpha \tau \varepsilon \sigma \varkappa \varepsilon v \alpha \sigma \mu \varepsilon ́ v o v)$ bereitet“; in der Apostelgeschichte nennt er dann die Glaubens- und Lebensweise der frühen Christen wiederholt „,den Weg“ ${ }^{60}{ }^{60}$ Matthäus wiederum zitiert Jesus in Mt 21,31f. mit den Worten, Johannes sei seinen jüdischen Zeitgenossen ,auf dem Weg der Gerechtigkeit“, d. h. als Prediger dieses Weges (vgl. V. 28-30) gegenübergetreten, sodass diejenigen, die ihm "geglaubt“, d. h. seiner Predigt entsprochen haben, ,in das Reich Gottes“ eingehen - ein Reich, das im irdischen Wirken Jesu präsent wird (vgl. 12,28); ${ }^{61}$ die Hörer und Täter der Lehre Jesu, die „,zuerst nach dem Reich und seiner Gerechtigkeit“ trachten (6,33), betreten dann eben damit den „mühseligen Weg, der ins Leben führt" $(7,14)$.

So bieten Matthäus und Lukas weitgehend übereinstimmende Interpretationen jenes Schriftwortes, das Markus in Mk 1,2b-c anführt: In ihrer Sicht kündigt es die Beauftragung und das Auftreten des Täufers an, der dem Gottesvolk den Weg zur Teilhabe an der Vollendung der Gottesherrschaft bahnt, indem er es auf den Weg der Gerechtigkeit ruft und lenkt.

Wie aber ist das Fehlen einer Parallele zu Mk 1,2b-c in Mt 3,3 und Lk 3,4 zu erklären? Für die Annahme der Verarbeitung einer zweiten, von Markus unabhängigen schriftlichen Quelle (etwa der Logienquelle Q), die das Auftreten des Täufers allein mit dem Jesajazitat verknüpfte, bieten die stark voneinander abweichenden Textabschnitte Mt 3,1-6 und Lk 3,1-6 nicht genügend Indizien. ${ }^{62}$ Wahrscheinlicher ist es, dass Matthäus und Lukas eine entsprechende mündliche

59 Vgl. N. Walter, Johannes und Jesus - zwei eschatologische Propheten. Das Selbstbild Jesu im Spiegel seines Bildes vom Täufer nach Q/Lk 7,24-35, in: U. H. J. KörTnER (ed.), Jesus im 21. Jahrhundert. Bultmanns Jesusbuch und die heutige Jesusforschung, NeukirchenVluyn 2002, 135-151, hier 141f., der den Bezug auf Jesus aber dennoch nicht in Frage stellt.

60 Vgl. Apg 9,2; 19,9.23; 22,4; 24,14.22, ferner 2,28 (,Wege des Lebens“); 13,10 (,,die geraden Wege des Herrn“); 16,17 (,Weg des Heils“); 18,25 (,,der Weg des Herrn“).

61 Zur matthäischen Unterscheidung des auf Erden durch Jesus vergegenwärtigten Gottesreiches von dem durch die Auferweckung Jesu begründeten Reich des Menschensohns und vom künftig-himmlischen Reich des Vaters vgl. WiLk, Jesus und die Volker, 85-87.118-120.133f.

62 J. M. Robinson / P. Hoffmann / J. S. Kloppenborg (edd.), The Critical edition of Q. Synopsis including the Gospels of Matthew and Luke, Mark and Thomas with English, German and French Translations of Q and Thomas, Leuven/Minneapolis 2000, verzeich- 
Überlieferung kannten, wie sie sich auch in Joh 1,(19-)23 niedergeschlagen haben dürfte. ${ }^{63}$ Gemeinsam mit der hinter Mt 11,7-11// Lk 7,24-28 stehenden Tradition, die Jesus als Sprecher des Zitats in Mt 11,10 // Lk 7,27 präsentiert, bot sie einen hinreichenden Grund, dessen Parallele im auktorialen Schriftzitat Mk 1,2f. zu übergehen. Diese Erklärung liegt umso näher, als die Abschnitte Mt 3,1-6 und Lk 3,1-17, wie dargelegt, ganz auf das Jesajazitat ausgerichtet sind und von ihm her ihre innere Stringenz erhalten. Die weiter gehende These, Matthäus und Lukas hätten eine jüngere oder ältere als die kanonische Fassung des MkEv verwendet, in der Mk 1,2b-c bereits bzw. noch gefehlt habe, ${ }^{64}$ ist dann unnötig; sie lässt sich vom Textbefund in Mk 1,1-4 // Mt 3,1-3 // Lk 3,1-6 her auch nicht stichhaltig begründen.

Wenn aber das in Mk 1,2b-c zitierte Schriftwort und der in V. 2a.3.4 erkennbare Zusammenhang außerhalb des $\mathrm{MkEv}$ unabhängig voneinander überliefert sind, dann steht zu vermuten, dass auch Markus das Schriftwort aus gesonderter Überlieferung kannte; er hat es also selbst in den genannten, eher traditionellen als erst redaktionell geschaffenen ${ }^{65}$ Zusammenhang eingefügt und diesem dann V. 1 vorangestellt. Der auktoriale Charakter von V. 2f. spricht allerdings gegen die Annahme, dass ihm jenes Schriftwort als ein Zitat im Munde Jesu bekannt war. ${ }^{66}$ Daher muss offen bleiben, ob er es aus Überlieferungen von Anhängern des Täufers, aus jüdischer oder aus frühchristlicher Tradition entlehnt hat - und ob es hier oder dort schon mit den Versen 6-8 oder $7 f$. verbunden war. ${ }^{67}$

Mit der Einfügung von Mk 1,2b-c und der Voranstellung von V. 1 hat Markus nun freilich selbst die Unklarheiten geschaffen, die V. 1-4 kennzeichnen: Das zuerst angeführte Schriftwort verliert ohne seinen angestammten Kontext jene referentielle Eindeutigkeit, die ihm etwa in Mt 11,10 / Lk 7,27 zukommt, und eröffnet

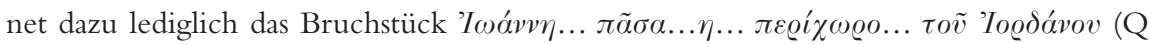
$3,2 \mathrm{~b}-3 \mathrm{a})$.

63 Siehe o. Anm. 27 (man beachte den von Mk 1,3 // Mt 3,3// Lk 3,4 abweichenden Wortlaut).

64 Vgl. z. B. einerseits A. Fuchs, Exegese im elfenbeinernen Turm. Das quellenkritische Problem von Mk 1,2-8 par Mt 3,1-12 par Lk 3,1-17 in der Sicht der Zweiquellentheorie und von Deuteromarkus, in: SNTU 20 (1995), 23-149, andererseits N. WaLTER, Mk 1,1-8 und die ,agreements“ von Mt 3 und Lk 3. Stand die Predigt Johannes des Täufers in Q?, in: F. Van Segbroeck et al. (edd.), The Four Gospels 1992. FS Frans Neirynck, Vol. 1 (BETL 100), Leuven 1992, 457-478.

65 Gegen J. ZMijewski, Markinischer «Prolog» und Täufertradition. Eine Untersuchung zu Mk 1,1-8, in: SNTU 18 (1993), 41-62: Nur V. 2b-c.6-8 sei traditionell, V. 2a.3-5 gehe auf die markinische Redaktion zurück.

66 Gegen J. Lambrecht, John the Baptist and Jesus in Mark 1.1-15. Markan Redaction of Q?, in: NTS 38 (1992), 357-384, der den markinischen Text als Bearbeitung einer QTradition auffasst.

67 So z. B. R. P. Merendino, Testi anticotestamentari in Mc 1,2-8, in: RivBib 35 (1987), $3-$ 25 (er sieht in Mk 1,2a.3-4.5* und V. 2a*.2b-c.6-8 zwei ursprünglich selbständige Traditionen unterschiedlicher Herkunft) bzw. J. Gnilka, Das Evangelium nach Markus. 1. Teilband: Mk 1-8,26 (EKK II/1), Zürich/Neukirchen-Vluyn ${ }^{4}$ 1994, 40f. (Mk 1,2b-c und V. 7f. gehören zusammen, da sich beide mit Q-Traditionen berühren). 
in der Kombination mit dem Jesajazitat auch für dieses weitere Deutungsmöglichkeiten; die Kopfzeile in V. 1 wiederum erlaubt neue syntaktische Zuordnungen für V. 2-4. So erhebt sich am Ende des synoptischen Vergleichs die Frage, ob die Mehrdeutigkeit der ersten Verse des MkEv ihrer Pragmatik entsprechen könnte.

Oder eignet den in V. 2f. kombinierten Schriftworten von ihrer Herkunft her ein eindeutiger Sinn? Diese Frage gilt es nun nachzugehen.

\section{Zur Textgestalt des Zitats in Mk 1,2f.}

Der handschriftliche Befund zur Textgestalt des Zitats wird aus der untenstehenden Übersicht ersichtlich. ${ }^{68}$ Im Einzelnen ist dazu Folgendes festzustellen:

a) In Mk 1,3 wird - der Einleitung 1,2a entsprechend ${ }^{69}$ - Jes 40,3 zitiert. Dabei liegt dem Zitat allem Anschein nach eine Septuagintafassung des Prophetenwortes zugrunde. Während nämlich $\mathrm{Mk}$ 1,3 in seinem wahrscheinlich ursprünglichen Wortlaut $^{70}$ mit dem Hauptstrom der Überlieferung zu Jes $40,3^{\text {LXX }}$ weitgehend bis auf eine Differenz am Versende ${ }^{71}$ - übereinstimmt, ${ }^{72}$ bestehen vor allem bei 40,3b beachtliche Divergenzen zwischen dem hebräischen und dem griechischen Text: In Letzterem fehlt ein Äquivalent für בערבה, ist der Sing. מסלה - pluralisch übersetzt ${ }^{73}$ und wird die folgende präpositionale Wendung nicht - wie zu erwarten wäre ${ }^{74}-$ durch einen Dativ, sondern durch einen Genitiv wiedergegeben. ${ }^{75}$

68 Siehe u. S. 221. Die Textwiedergabe folgt den kritischen Ausgaben der Göttinger Septuaginta und des Novum Testamentum Graece (Stuttgart 1993, 8. Druck 2001). Die Bezeugung alternativer Lesarten ist in den Fußnoten zur Übersicht dokumentiert; dabei sind Varianten, die für das Verhältnis zwischen Mk 1,2f. und den dort angeführten Schriftworten offensichtlich irrelevant sind, nicht berücksichtigt.

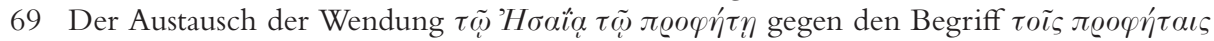
in den Hss. A K P W $\Gamma f^{13} 2810101424 \mathfrak{w r}^{\text {sy }^{\mathrm{h}}}$ (bo $^{\text {mss }}$ ) bringt die nicht-jesajanische Herkunft von Mk 1,2b-c (s. u.) zum Ausdruck und ist daher - als lectio potior - ohne Zweifel sekundär.

70 In Mk 1,3 dürften die schwach bezeugte Lesart $\tau$ v $\vartheta \varepsilon o \tilde{v} \eta \tilde{\omega} v$ (Fn. g) auf einer sekundären Angleichung an Jes $40,3^{\mathrm{LXX}}$ und der lediglich in zwei Hss. vorhandene Zusatz von Jes 40,4-8 (Fn. h) auf dem Paralleleinfluss von Lk 3,5f. beruhen.

71 Dazu s. u. Absatz b).

72 Die Einfügung von $\delta \iota \dot{\alpha} \tau \tilde{\eta} \varsigma \dot{\alpha} \beta a ́ \tau o v$ in diversen Zeugen der lukianischen Rezension (Fn. c - zur Einordnung der Zeugen vgl. J. Ziegler [ed.], Isaias [Septuaginta. Vetus Testamentum Graecum Auctoritate Academiae Scientiarum Gottingensis editum XIV], Göttingen ${ }^{3} 1983$, 74-81) ist höchstwahrscheinlich einer sekundären Annäherung an den MT geschuldet.

73 Die einzige Analogie bietet Spr 16,17 ${ }^{\mathrm{LXX}}$; der Pl. $\tau \varrho$ í $\beta o \iota$ entspricht dort freilich dem Pl. $\delta \delta o v ́ \varsigma$ in V. 17b und ist überdies angesichts des im MT vorliegenden status constructus מסלת orthographisch leicht zu erklären.

74 Vgl. Gen 46,1 u. ö.

75 Vgl. dagegen die bei Euseb bezeugte wörtliche Übersetzung des Symmachus (Fn. a). 
Die zwei letztgenannten Modifikationen verstärken die Parallelität und den Zusammenhang der beiden Aufforderungen. ${ }^{76} \mathrm{Ob}$ aber - wie meist behauptet ${ }^{77}$ - die Wendung $\dot{\varepsilon} v \tau \tilde{\eta}$ हैo $\eta_{\mu \omega}$ aufgrund des Fehlens eines Pendants in Jes 40,3b zum Voranstehenden gezogen werden muss, ist zweifelhaft. In der Jesaja-LXX wird häufig auf die Wiedergabe eines synonymen Wortes im parallelen Satzglied verzichtet ${ }^{78}$ und an dieser Stelle kann man daraufhin einen synthetischen

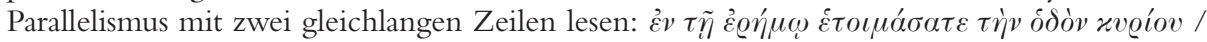

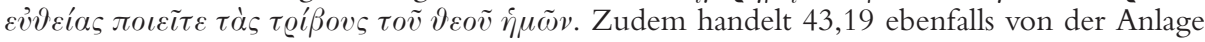

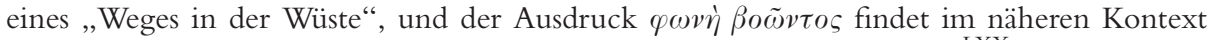

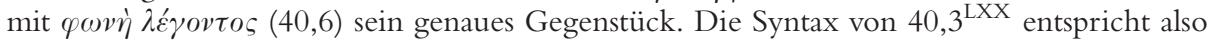
vermutlich der des hebräischen Originals.

Auch in Jes 40,3a weist die der LXX und dem MkEv gemeinsame Fassung ein spezifisches Profil gegenüber dem Masoreten-Text (MT) auf, ist doch die Wiedergabe

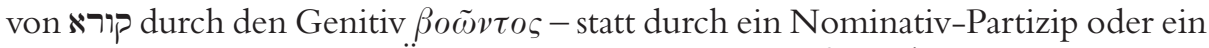

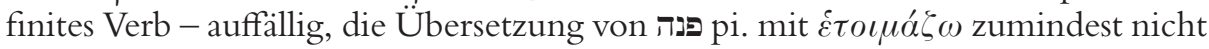
selbstverständlich. ${ }^{79}$ Ein direkter, unabhängig von der Septuaginta erfolgter Rückgriff auf den hebräischen Text von Jes 40,3 ist deshalb für Mk 1,3 auszuschließen. Vielmehr basiert das Zitat auf der in den meisten Textzeugen dokumentierten LXX-Fassung von Jes 40,3.

b) In der Textüberlieferung zu Jes $40,3^{\text {LXX }}$ ist die Lesart $\alpha \dot{v} \tau o \tilde{v}$ (Fn. d) nur in drei späten Hss., ${ }^{80}$ der sahidischen Übersetzung und bei drei Kirchenvätern belegt. Diese sehr schwache Bezeugung legt den Schluss nahe, dass die genannte Lesart auf eine spätere Angleichung des LXX-Wortlauts an den von Mk 1,3 (sowie Mt 3,3; Lk 3,4) zurückgeht. In Mk 1,3 muss avं den; wahrscheinlich geht die Einfügung dieses Pronomens anstelle der dem MT entsprechenden Wendung $\tau$ о $\tilde{v} \vartheta \varepsilon о \tilde{v} \dot{\eta} \mu \tilde{\omega} v$ auf den Urheber des Zitats im MkEv zurück. In formaler Hinsicht verändert er damit die Länge der letzten Zeile, sodass die Stellung der Angabe ,in der Wüste“ zwischen Einleitungswendung und erster Aufforderung in die Schwebe gerät. Sachlich gesehen, sorgt er auf diese Weise dafür, dass in dem zitierten Aufruf ausschließlich vom xúøı gesprochen wird. Daraus folgt zweierlei: 1. Die Identität des „Herrn“ kann nicht mehr weder differenzierend noch identifizierend - vom Bezug auf ,,unseren Gott" her bestimmt werden; 2. der Sprecher des Aufrufs erscheint nicht mehr als Vertreter einer ,Wir“-Gruppe, die durch eine allen gemeinsame Gottesbeziehung konstituiert wird. Wird aufgrund des ersten Faktors eine christologische Interpretation

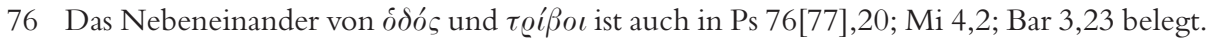

77 Vgl. nur das Druckbild bei Ziegler (ed.), Isaias, z. St.

78 Vgl. J. Ziegler, Untersuchungen zur Septuaginta des Buches Isaias (ATA 12,3), Münster 1934, 51f.

79 Die einzige Parallele dazu bietet - bezogen auf „das Haus“ - Gen 24,31. Sonst ist פנה פנ.

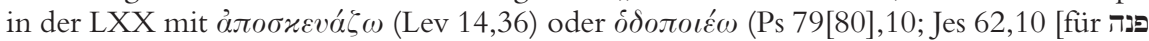
דרך] übersetzt (zu Mal 3,1 s. u. Anm. 86; in Zef 3,15 wurde das Verb im Bezug auf,,dei-

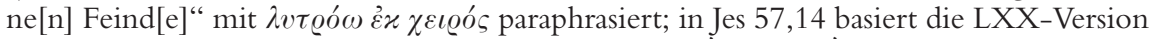

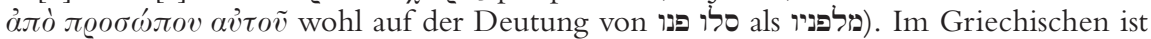
die Verknüpfung von $\dot{\varepsilon} \tau o \iota \mu \alpha ́ \zeta \omega$ mit $\dot{\eta} \delta \delta \delta ́ \varsigma$ freilich noch öfter belegt; vgl. in der LXX 2Chr 27,6; Hi 38,25, im NT Lk 1,76; Apk 16,12.

80 Vgl. zu den genannten Hss. die Übersicht bei Ziegler (ed.), Isaias, 7-11. 
des Jesajazitats jedenfalls prinzipiell möglich, so führt der zweite Faktor dazu, dass die Identität des „Rufenden“ nicht mehr eindeutig auf einen im Namen Israels sprechenden Menschen festgelegt ist. ${ }^{81}$

c) Das Zitat in Mk 1,2b-c lässt sich als Ganzes weder aus der griechischen noch aus der hebräischen Überlieferung des Alten Testaments (AT) herleiten. Vielmehr liegt ein Mischzitat vor, ${ }^{82}$ dessen Bausteine jedoch ziemlich klar erkennbar sind: Einerseits stimmt Mk 1,2b mit dem ersten Teilsatz von Ex 23,20 fast wörtlich überein. ${ }^{83}$ Dabei spricht die Konvergenz von LXX und MkEv in dem - gegen den $\mathrm{MT}^{84}-\mathrm{zu} \tau \dot{o} v \not \check{\alpha} \gamma \gamma \varepsilon \lambda o v$ hinzugefügten Personalpronomen $\mu o v$ für die Aufnahme einer Septuagintaversion.

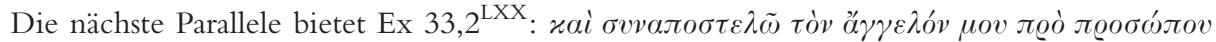

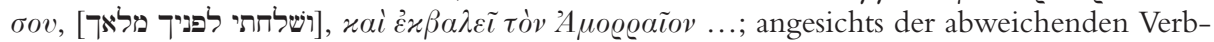
form und des Fehlens von idov́ ist eine Einwirkung auf Mk 1,2b jedoch unwahrscheinlich. ${ }^{85}$

Andererseits entspricht das ganze Zitat in seinen wesentlichen Bestandteilen Mal 3,1a. Zwar weicht die LXX-Überlieferung zu diesem Prophetenwort an mehre-

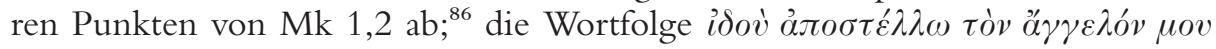
..., ó dar. Allerdings ist ein direkter Rückgriff auf den hebräischen Text unwahrscheinlich. ${ }^{87}$ Dagegen spricht schon die Kombination mit dem der Septuaginta entlehnten Exodus-Wort. Vor allem aber liegt mit dem Relativpronomen ö́ eine deutende Wiedergabe der Konjunktion I vor, wie sie in der

$81 \mathrm{Zu}$ diesem Profil der Rede von „unserem Gott“ in der Jesaja-LXX vgl. 25,9; 26,12f.; 35,$4 ; 36,7 ; 37,20 ; 40,8 ; 59,13$ sowie $52,10^{\text {SBV etc. }}$, ferner als Gegenstück 42,17: „Ihr seid unsere Götter!“

82 Während in einer Zitatkombination zwei syntaktisch selbständige Schriftworte aneinandergefügt werden, wie es etwa in 1Kor 15,54f. geschieht, wird bei einem Mischzitat der Wortlaut des grundlegenden Schriftworts durch Einfügung eines Textsegments (oder mehrerer Textsegmente) aus einem anderen Schriftwort verändert (vgl. z. B. Röm 9,27f.33); vgl. dazu WiLk, Bedeutung des Jesajabuches, 51-59.

83 Da $\dot{\varepsilon} \gamma \omega^{\prime}$ in den allermeisten Textzeugen zu Ex 23,20 ${ }^{\mathrm{LXX}}$ belegt ist (Fn. n), dürfte es im Zuge der handschriftlichen Überlieferung von Mk 1,2b (Fn. e) eher (zur Angleichung an das AT) sekundär ergänzt als sekundär gestrichen worden sein. Vielleicht hat dabei auch Mt 11,10 eingewirkt; freilich ist in der Parallelstelle Lk 7,27 das $\dot{\varepsilon} \gamma \omega^{\prime}$ nicht vorhanden.

84 Bezeugt ist das Suffix nur im Samaritanus; ein Äquivalent bietet allerdings auch der Großteil der Vulgata-Überlieferung z. St. (s. Fn. r).

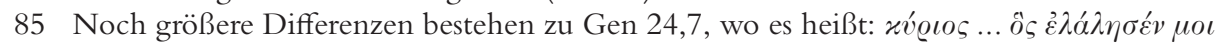

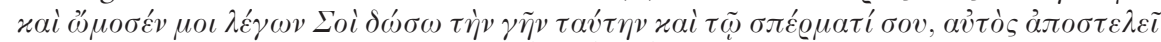

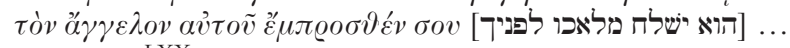

86 In Mal 3,1 ${ }^{\mathrm{LXX}}$ erscheint als erstes Verb das (unisono bezeugte, lediglich in manchen Hss. ins

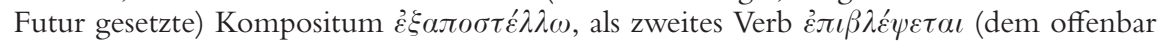
die Deutung von פנה als qal-Form zugrunde liegt, vgl. Lev 26,9 u. Ö.); zudem fehlt der Artikel vor ódóv.

87 Gegen H. J. Steichele, Der leidende Sohn Gottes. Eine Untersuchung einiger alttestamentlicher Motive in der Christologie des Markusevangeliums (BU 14), Regensburg 1980, 63. 
LXX auch andernorts belegt ist, ${ }^{88}$ nicht zuletzt in dem Mal 3,1 sprachlich und inhaltlich nahe stehenden Satz 4,4f.[3,23f.] ${ }^{89}$ Deshalb dürfte Mk 1,2 eine nach dem hebräischen Original überarbeitete Fassung der Septuagintaversion von Mal 3,1 zugrunde liegen - und damit zugleich eine Textfassung, die den Zusammenhang dieses Prophetenwortes mit Mal 3,23f. ${ }^{\mathrm{MT}}$ deutlicher hervortreten lässt als der älteste LXX-Text. Für die Annahme solch einer Überarbeitung spricht auch die Verwendung von $\varkappa \alpha \tau \alpha \sigma \varkappa \varepsilon v \alpha ́ \zeta \omega$, stammt es doch aus derselben Wortgruppe wie die Verben $\sigma \varkappa \varepsilon v a ́ \zeta \omega$ und $\alpha \dot{\pi} \sigma \kappa \varkappa v \alpha \alpha \zeta \omega$, welche in den (hexaplarischen Resten der) jüngeren griechischen Übersetzungen wiederholt und gerade im Zusammenhang der Wegbereitung für פנה pi. stehen - bei Aquila übrigens auch in Mal 3,1! ${ }^{90}$

Ob die Mk 1,2 zugrunde liegende Textfassung von Mal 3,1 ein $\dot{\varepsilon} \gamma \omega^{\prime}$ enthalten hat oder nicht, muss offen bleiben. Das Pronomen könnte im Zuge der Annäherung an den hebräischen Text gestrichen worden sein; Röm 9,33 und 1Petr 2,6 bezeugen ja eine rezensierte Version von Jes

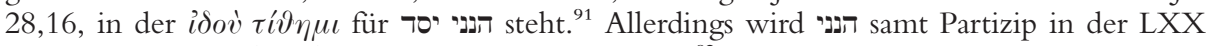
regelmäßig mit $i \delta o \dot{v} \varepsilon \dot{\gamma} \gamma \omega ́$ samt finitem Verb übersetzt. ${ }^{92}$ Andererseits ist angesichts der gespaltenen handschriftlichen Überlieferung zu Mal 3,193 durchaus denkbar, dass die Revision schon einen Text ohne $\dot{\varepsilon} \gamma \omega^{\prime}$ vorgefunden hat. Doch wie die Anführung von Ex 23,20f. durch Philo in Migr. 174 belegt, kann dieses Pronomen bei der Zitation auch ohne erkennbare Absicht und ohne Auswirkung auf den Textsinn - entfallen. ${ }^{94}$

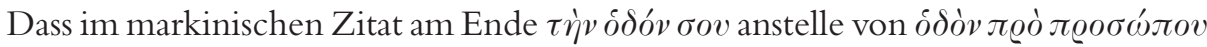
$\mu o v$ steht, ${ }^{95}$ ist dann als Modifikation des Textes im Sinne von Ex 23,20 anzusehen; dort besteht die Aufgabe des Gesandten ja darin, ,dich“ auf dem „Weg“ zu

88 Vgl. Gen 35,3 u. ö.

89 Die Bezeugung des Relativpronomens in Ex 23,20 allein durch lateinische Zeugen (Fn. p) ist zu schwach, als dass man ö $\zeta$ in Mk 1,2 von dort herleiten könnte (auch wenn die Wiedergabe des mit $ל$ angeschlossenen Infinitivs durch einen Relativsatz ihrerseits Parallelen in der Septuaginta hat; vgl. Gen 19,31 u. ö.).

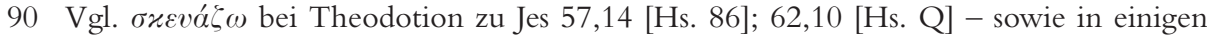
LXX-Hss. (V, 22-48-51-231-763-62-90-130-311, 403-613 544 770) und bei Theodoret

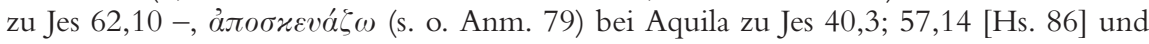
Mal 3,1 (Fn. k), bei Symmachus zu Ps 79[80],10, bei Theodotion zu Jes 40,3 und (!) 62,10 [Hs. 86]. - Dass Mk 1,2 eine von der Septuaginta unabhängige griechische Übersetzung des hebräischen Textes von Mal 3,1 widerspiegelt (so Marcus, The Way of the Lord, 13), ist deshalb unwahrscheinlich.

91 Vgl. Wilk, Bedeutung des Jesajabuches, 31-34. - Statt יסד lesen 1QJes מוסד und 1QJes דיוסי.

92 In der LXX-Überlieferung wird - bei insgesamt über 110 Belegen - diese Regel nur an wenigen Stellen durch eine namhafte Zahl von Textzeugen durchbrochen; vgl. Num 24,14; 2Chr 34,28; Jes 13,17; 38,5, mit Einschränkung auch Jes 29,14; 38,8; 43,19; Ez 29,19. Zum Befund im Jesajabuch vgl. ZiEgler (ed.), Isaias, $97 \mathrm{f}$.

93 Siehe Fn. i.

94 Da Philo Ex 23,20a in Agr. 51 mit $\dot{\varepsilon} \gamma \omega \dot{~ z i t i e r t ~ u n d ~ d a s ~ P r o n o m e n ~ d a n n ~ d u r c h ~ d e n ~ Z u s a t z ~}$ von ei ui zur Präsentationsformel ausbaut, darf man von Migr. 174 nicht auf eine ihm bekannte Textfassung ohne $\dot{\varepsilon} \gamma \omega \dot{\omega}$ schließen.

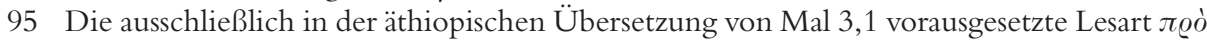

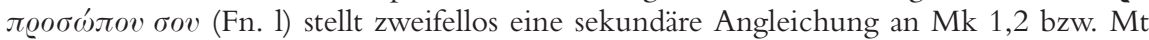
11,10 // Lk 7,27 dar. Auf den späteren Einfluss der beiden letztgenannten Stellen dürfte 
bewahren. Auf die gewählte Formulierung hat vielleicht Gen $24,40^{\text {LXX }}$ eingewirkt, ${ }^{96}$ wo Abraham von seinem zur Brautschau entsandten Knecht im Gespräch

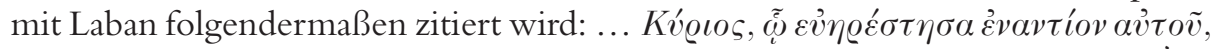

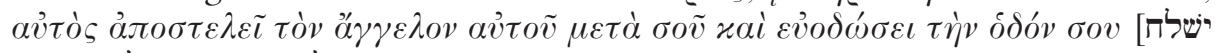
[מלאכו אתך והצליח דרכך ... Da dieser Satz jedoch ganz auf die Gewinnung einer Frau für Isaak ausgerichtet ist, ist ein sachlicher Zusammenhang mit dem Zitat in Mk 1,2f. so gut wie ausgeschlossen.

Zusammenfassend lässt sich zum Zitat in Mk 1,2 feststellen: Es basiert aller Wahrscheinlichkeit nach auf einer anhand des hebräischen Textes revidierten Septuagintaversion von Mal 3,1a, die vermutlich folgenden Wortlaut hatte: $i \delta o \dot{v}$ [ $\dot{\varepsilon} \gamma \dot{\omega}]$

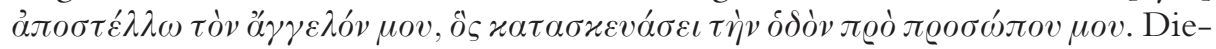
ses - ggf. um das Pronomen $\grave{\varepsilon} \gamma \omega ́$ gekürzte - Prophetenwort wurde dann mit zwei Elementen aus Ex 23,20a ${ }^{\text {LXX }}$ durchsetzt: ${ }^{97}$ Am Ende des Hauptsatzes wurde $\pi \varrho o ̀ ~ \pi \varrho o \sigma \omega ́ \pi 0 v \sigma o v$ eingefügt, am Ende des Relativsatzes die fast gleichlautende Schlusswendung aus Mal 3,1a durch das Personalpronomen der 2. Person Sing. ersetzt. $^{98}$ Es ergibt sich also folgendes Bild:

\begin{tabular}{|c|c|c|}
\hline Mal 3,1 $\mathrm{a}^{\mathrm{LXX}(\text { rev.) }}$ & Mk 1,2 & Ex $23,20 a^{L X X}$ \\
\hline 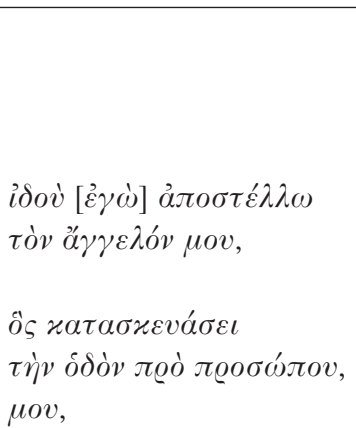 & 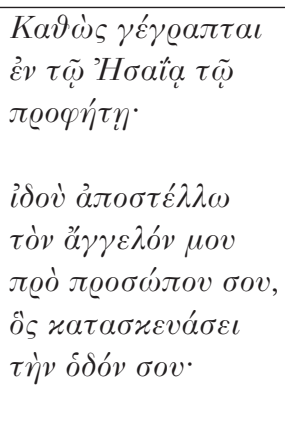 & 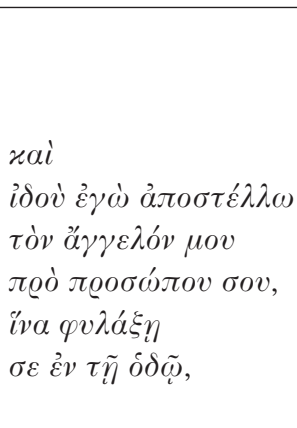 \\
\hline
\end{tabular}

dann seinerseits der zwar vielfach, qualitativ gesehen aber nur zweitrangig bezeugte Zusatz

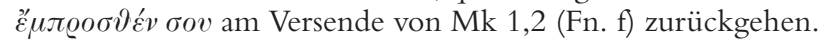

96 Von der Bereitung ,deines Wegs“ ist innerhalb der LXX sonst nur noch an zwei Stellen die Rede: In Jos 1,8 wird die Ermahnung Josuas zur unablässigen Bindung an „,das Buch

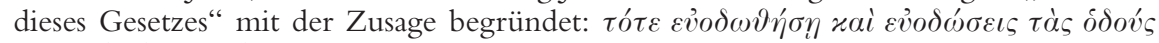

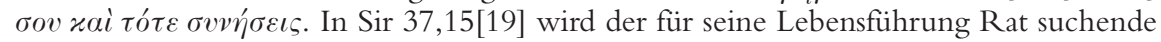

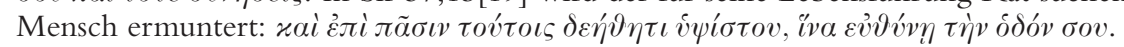

97 Die Nähe dieser beiden Bibelstellen zueinander wurde auch in der rabbinischen Exegese ausgewertet; vgl. etwa ExR 32,9, auszugsweise übersetzt bei H. L. STrack / P. BillerBECK, Kommentar zum Neuen Testament aus Talmud und Midrasch, Vol. 1, München ${ }^{2}$ 1956, 597. Eine Parallele zum Mischzitat ist damit aber nicht gegeben.

98 Natürlich könnte man die Genese des Zitats in Mk 1,2 auch von Ex 23,20a aus beschreiben: Der Urheber hat den ersten Satz - unter Tilgung des einleitenden xai und des Personalpronomens $\dot{\varepsilon} \gamma \omega \dot{\omega}$ - aus Ex 23,20 übernommen, die Fortsetzung dann durch den zweiten Satzteil von Mal 3,1a ersetzt, dessen Ende aber wiederum in Anlehnung an Ex 23,20a modifiziert. Das im Haupttext gewählte Modell liegt jedoch näher, weil es einfacher strukturiert ist und mit ihm ein Schriftwort als Grundlage des gesamten Zitats erscheint. 
Diese Vermischung führt dazu, dass der Gesandte dem Zitat in Mk 1,2 zufolge

- anders als in Ex 23,20 nicht als Beschützer, sondern als Wegbereiter erscheint und dabei

- anders als in Mal 3,1 statt seinem Auftraggeber dem mit „du“ Angeredeten vorausgeht.

Das bedeutet in der Sache: Der Weg, den der Bote Gottes bahnt, um die eschatologische Begegnung Gottes mit Israel vorzubereiten (Mal 3,1), wird als der Weg identifiziert, den jener Bote für das Gottesvolk bahnt, damit es darauf den Ort der Verheißung erreicht (Ex 23,20); und damit erhält das Begehen dieses Weges den Charakter einer endzeitlichen „Landnahme“.

d) Dieser Charakter des Mischzitats aus Mal 3,1 $\mathrm{a}^{\mathrm{LXX}(\mathrm{rev} .)}$ und Ex 23,20a $\mathrm{a}^{\mathrm{LXX}}$ entspricht nun recht genau der Eigenart des Zitats aus Jes 40,3 $3^{\text {LXX}}$; dieses redet ja seinerseits so vom eschatologischen Kommen Gottes, dass Gott selbst sein Volk aufs Neue an den Ort der Verheißung führt. ${ }^{99}$ Insofern erwächst erst aus der Vermischung der beiden erstgenannten Schriftworte die Möglichkeit, sie mit dem dritten zu einer Zitatkombination zusammenzufügen, die dem Propheten Jesaja zugeschrieben werden kann. Umgekehrt erleichtert die Wortlautänderung am Ende des Jesajazitats dessen Anschluss an das Mischzitat; denn nun lässt sich jenes „Rufen“ ohne Weiteres sowohl auf den Sender als auch auf den Gesandten in Mk 1,2 zurückführen.

Das zentrale Ergebnis der Zusammenstellung aller drei Schriftworte besteht dann darin, dass das Misch- und das Jesajazitat sich wechselseitig erläutern. Dies kann freilich auf verschiedene Weisen erfolgen. Unter der Voraussetzung, dass der Sprecher von Mk 1,2b-c kein anderer als der in V. 3 genannte „Herr“ sein kann, sind folgende Möglichkeiten gegeben:

1. Geht man vom sachlichen Impetus des Mischzitats aus Mal 3,1 und Ex 23,20 aus, die Vorbereitung der endzeitlichen Begegnung zwischen Gott und dem Gottesvolk anzukündigen, so liegt es nahe, die Zitatkombination als expliziten Ausdruck der Konvergenz ihrer jeweiligen Wege zu verstehen: Der Weg des Gottesvolkes an den Ort des endzeitlichen Heils, den der Bote Gottes nach Mal 3,1 / Ex 23,20 bahnen soll, ist mit dem in Jes 40,3 genannten ,Weg des Herrn“ identisch. Deshalb wird jener Weg des Gottesvolkes gerade dadurch gebahnt, dass der dafür zuständige Bote im Volk auftritt und dort den „Weg des Herrn“ bereitet bzw. bereiten lässt. In $\mathrm{Mk}$ 1,2 wäre demnach das Gottesvolk angesprochen, und der ihm vorausgeschickte „Bote“ des „Herrn“ würde in V. 3 entweder berufen oder mit seiner Botschaft zitiert.

2. Orientiert man sich hingegen an der Machart des Mischzitats in V. 2, bei der die Rede vom Kommen Gottes aus Mal 3,1 durch Hinweise auf den Weg des in der 2. Person Sing. angesprochenen Gottesvolkes nach Ex 23,20 ersetzt worden

99 Vgl. dazu auch Jes 41,3; 42,16. Die Zusammenstellung beider Zitate beruht also keineswegs auf der Konvergenz in dem hebräischen Ausdruck „den Weg bereiten“ (so KaTZ, Wie einer der Propheten? Das biblische Markusevangelium als Darbietung eines «Vorevangeliums», 55). 
ist, so liegt es nahe, jenes ,du“" nun seinerseits im Rahmen der neu geschaffenen Zitatkombination, also von V. 3 her, zu deuten. Dann gälte die Anrede dem eschatologischen Repräsentanten Gottes, in dessen (seinerseits von einem Boten vorbereiteten) Wirken sich das Kommen Gottes zu seinem Volk realisiert. V. 3 kann dann wiederum als Berufungswort aufgefasst werden, das sich an den „Boten“ - oder zugleich an ihn und jenen Repräsentanten Gottes - richtet, aber auch als Wiedergabe seiner Botschaft.

Demzufolge sind letztlich alle o. g. Möglichkeiten der Deutung des Zitats Mk 1,2f., die sich aus der Untersuchung seines markinischen Verwendungszusammenhangs ergaben, ${ }^{100}$ mit der Textgestalt dieser Zitatkombination vereinbar. So verfestigt sich der Eindruck, ${ }^{101}$ dass die Mehrdeutigkeit des Anfangs der markinischen Jesuserzählung mit seiner Intention verknüpft sein könnte.

$\mathrm{Zu}$ prüfen bleibt freilich noch, in welchem Maße Markus die ursprünglichen Kontexte der angeführten Schriftworte im Zuge der Zitation rezipiert hat; möglicherweise ergeben sich daraus neue Gesichtspunkte für das Verständnis des Zitats.

\section{Zur Rezeption der Kontexte der in Mk 1,2f. kombinierten Schriftworte}

Aus methodischen Gründen halte ich es für geboten, die Frage nach etwaigen Bezügen auf die ursprünglichen Kontexte neutestamentlicher Schriftzitate so zu bearbeiten, dass man vom betreffenden Text des NT ausgeht. Es gilt also im Umfeld von $\mathrm{Mk}$ 1,2f. nach Übereinstimmungen oder Konvergenzen mit den Kontexten der dort angeführten Schriftworte zu suchen - und in strenger Ausrichtung an ihnen zu ermitteln, wie jene Kontexte im Sinne des Markus zu verstehen sind. ${ }^{102}$ Dieses Verfahren führt zu folgenden Ergebnissen:

a) Da Markus für die Kombination des Mischzitats Mk 1,2b-c mit dem Jesajazitat in V. 3 verantwortlich sein dürfte, ${ }^{103}$ ergibt sich schon daraus ein erster Beleg für seine Rezeption der biblischen Kontexte: Der Ausdruck „Weg des Herrn“ in Jes 40,3 erinnert an die Ankündigung in Mal 3,1b, dass ,,der Herr plötzlich ... kommen werde“. Dass dabei vom Kommen , in den Tempel“" geredet wird, entspricht der Angabe in Jes 40,9, die Kunde vom bevorstehenden Erscheinen Gottes

100 Siehe o. Abschnitt 3.

101 Siehe o. nach Anm. 67.

102 Vgl. zur Begründung F. WiLK, Paulus als Nutzer, Interpret und Leser des Jesajabuches, in: S. Alkier / R. B. Hays (edd.), Die Bibel im Dialog der Schriften. Konzepte intertextueller Bibellektüre (NET 10), Tübingen/Basel 2005, 93-116, hier 98-100; gegen P. J. SANKEy, Promise and Fulfilment: Reader-Response to Mark 1.1-15, in: JSNT 58 (1995), 3-18, hier 6-9, der zu Mk 1,2f. zuerst ,the settings of the three Old Testament passages“ betrachtet, um von ihnen aus die durch das Zitat beim Leser hervorgerufenen Erwartungen zu rekonstruieren - ohne doch sagen zu können, in welchem Umfang und wie dieser jene Kontexte wahrgenommen haben soll.

103 Siehe o. bei Anm. 65-67. 
ergehe an „Zion“. Der ganze Befund aber passt zur markinischen Darstellung des Weges Jesu, der von den Dörfern bei Cäsarea Philippi (Mk 8,27) durch Galiläa (9,[30.]33f.), Peräa (10,[1.]17) und Jericho $(10,46.52)$ nach Jerusalem $(10,32)$ und dort als erstes in das Heiligtum (11,8[.11]) führt. Das Ziel seines Weges aber besteht - Gottes Heilsplan gemäß $(8,31 ; 14,49)$ - in seiner Kreuzigung und Auferweckung (10,33f.). Daher liegt es nahe, die Rede vom ,Weg des Herrn“ in 1,3 als Hinweis darauf zu verstehen, dass durch den Gang Jesu nach Jerusalem Gott selbst seine eschatologische Herrschaft aufrichtet.

b) Die der Zitatkombination vorangestellte Kopfzeile $\alpha \varrho \chi \dot{\eta} \tau o \tilde{v} \varepsilon \dot{v} \alpha \gamma \gamma \varepsilon \lambda i ́ o v$

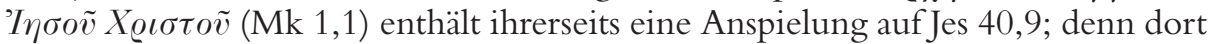

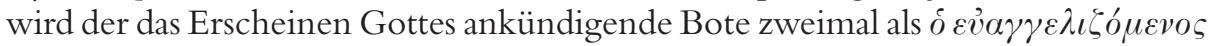
bezeichnet. Da dieser „,den Städten Judas“ sagen soll: „,Siehe, euer Gott!“, kann er im Sinne des Markus wohl am ehesten auf Jesus selbst gedeutet werden, der „das Evangelium Gottes“ verkündet, indem er das Nahesein der „Herrschaft Gottes“ ansagt und zum Glauben an das Evangelium aufruft (Mk 1,14f.). ${ }^{104}$ Die jenem Boten in Jes 40,9 zugeordnete Ermahnung „Fürchtet euch nicht!“"105 ermöglicht es freilich auch, ihn im Lichte von Mk 16,6-8 als Zeugen des auferstandenen Christus anzusehen, welcher im nachösterlichen Evangelium präsent wird; ${ }^{106}$ die weltweite Ausbreitung dieses Evangeliums, die Jesus nach 13,10 und 14,9 voraussagt, hätte dann ihre Entsprechung in Jes 40,5b: „Und alles Fleisch wird sehen die Rettung durch Gott; denn der Herr hat geredet." So unterstreicht der Anklang an Jes 40,9 gerade die Doppeldeutigkeit von Mk 1,1.

c) Die auf $M k$ 1,2f. folgende Darstellung der Tätigkeit des Täufers lässt gleich mehrere Stellen aus den Kontexten der zitierten Schriftworte anklingen: Dass Johannes denen, die von ihm die Taufe empfangen und umkehren, die

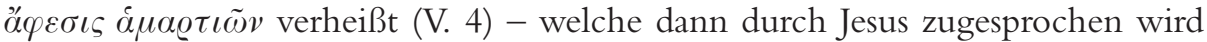
(2,5-11) -, entspricht der Botschaft von Jes 40,2: $\lambda \dot{\varepsilon} \lambda v \tau \alpha \iota \ldots \dot{\eta} \dot{\alpha} \mu \alpha \varrho \tau i ́ \alpha .{ }^{107}$ Dass diese Botschaft Jerusalem gilt $(40,2)$ - und der o. g. Freudenbote sich demzufolge an Zion, Jerusalem und die Städte Judas wendet $(40,9)-$, spiegelt sich in

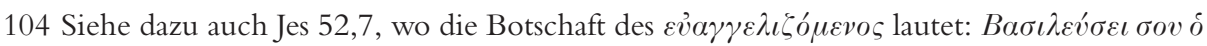

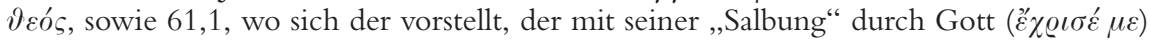

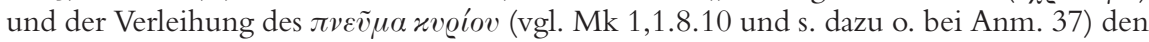
Auftrag $\varepsilon \dot{v} \alpha \gamma \gamma \varepsilon \lambda i \sigma \alpha \sigma \vartheta \alpha \iota \pi \tau \omega \chi \sigma \tilde{\iota} \varsigma$ erhalten hat.

105 Dabei ist im LXX-Text nicht ganz klar, ob dieser (gegen den MT im Pl. formulierte) Zuruf an eine (dann vorausgesetzte) Mehrzahl von Freudenboten ergeht oder ob er den Hörern des einen Freudenboten gilt.

106 Siehe dazu o. Anm. 13 und vgl. Mk 6,50 und 9,6 zur Furcht der Jünger angesichts von Epiphanien Jesu.

107 In Jes 40,2 $2^{\text {LXX }}$ erscheinen Priester als Sprecher dieser Botschaft; nur sie sind verbreitetem Denken gemäß befugt, im Namen Gottes Sündenvergebung zuzusprechen. Eben deshalb stößt der Zuspruch Jesu in Mk 2,5-7 auf den erbitterten Protest der Schriftgelehrten. Doch Markus zufolge errichtet Gott im Gefolge des Wirkens und auf der Basis des Todes Jesu einen neuen, himmlischen Tempel, sodass Vergebung fortan allein an den Glauben gebunden ist (vgl. 11,12-12,12 u. ö. und dazu WiLk, Jesus und die Völker, 43-50). Zu 1,4 s. o. Abschnitt 2.d). 
der Aussage wider, Johannes habe mit seiner Verkündigung ,das ganze judäische Land und alle Jerusalemer" erreicht (Mk 1,5). Dazu passt, in anderer Weise, nun auch die Ankündigung Mal 3,4, ,dem Herrn werde das Opfer Judas und Jerusalems gefallen wie in den Tagen der Vorzeit" - zumindest dann, wenn man sie im Anschluss an die Rede vom „Opfer in Gerechtigkeit“ (Mal 3,3) gemäß Ps 4,6; 50[51],21 metaphorisch versteht (vgl. Mk 12,33). ${ }^{108}$ Jedenfalls bietet der Um-

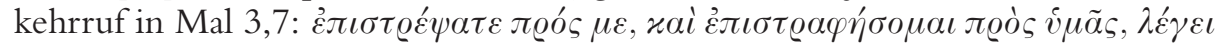

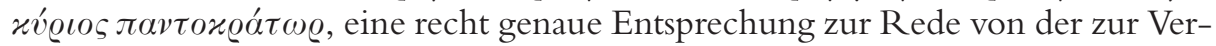
gebung führenden $\mu \varepsilon \tau$ ćvoı $\alpha$ in Mk 1,4; und der in V. 5 dargestellte Erfolg des Täufers erscheint dann als Erfüllung der Prophetie, dass die Söhne Jakobs - nach allerlei Einwänden - jedenfalls zum Teil von ihren Ungerechtigkeiten lassen, den Herrn fürchten und zu seinem Eigentum, zu Gottes Dienern werden (Mal 3,7-18). All

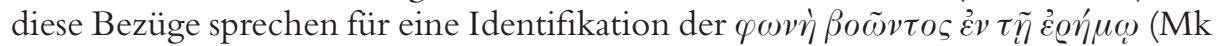
1,3a) mit Johannes; darüber hinaus aber führen sie zu je anderen Wahrnehmungen seines Wirkens. Von Jes 40,2.9 her erscheint er eher als ein Vorbote Jesu, sodass es sich empfiehlt, Mk 1,2b-c als Weissagung auf das Verhältnis dieser beiden zu lesen. Die Verknüpfungen mit Mal 3,3f.7-18 hingegen unterstreichen die Rolle des Täufers, das jüdische Volk auf Gottes Kommen vorzubereiten; sie stützen deshalb die Deutung von $M k$ 1,3b-c auf seine diesbezügliche Umkehrpredigt.

d) Die Beschreibung der Kleidung des Johannes in Mk 1,6 enthält mit dem Hinweis auf den ,ledernen Gürtel um seine Hüfte“ eine klare Anspielung auf 2Kön [4Regn] 1,8; dort wird erzählt, wie (u. a.) dieses Kleidungsstück die Identität seines Trägers enthüllt und ihn als „Elija, den Thesbiter“ ausweist. Insofern klingt in jener Beschreibung Mal 4,4[3,23]a an, wo Gott - mit ganz ähnlichen Worten

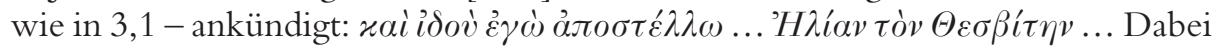
wird dieser Bote allerdings explizit als ,zu euch“"gesandt charakterisiert. Mit ihm lässt Gott nämlich, ,,bevor der große und leuchtende Tag kommt“, den auftreten, „,der das Herz des Vaters für den Sohn und das Herz des Menschen für seinen Nächsten wiederherstellen wird, auf dass ich nicht komme und die Erde völlig zerschlage“" (4,4b-5[3,23b-24]). Vor diesem Hintergrund liegt es nahe, Mk 1,2b-c auf die Bedeutung des Täufers für das Gottesvolk zu beziehen. Allerdings rezipiert Markus den ganzen Passus auch in Mk 9,11f.; und da Jesus dort das Geschick jenes „Elija“ als Vorzeichen für das Leiden des Menschensohns interpretiert, kann man den Rekurs auf Elija in Mk 1,6 durchaus auch als Indiz dafür werten, dass Johannes mit dem Zitat in 1,2b-c als Vorbote und Wegbahner Jesu ausgewiesen wird.

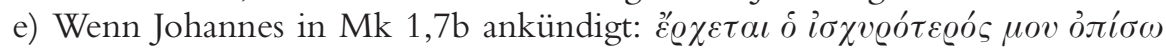
$\mu o v$, so erinnert dies zum einen an Mal 3,1, wo die Rede vom plötzlichen Kom-

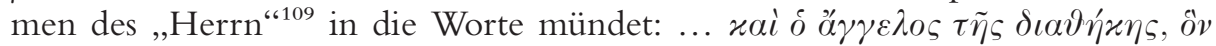

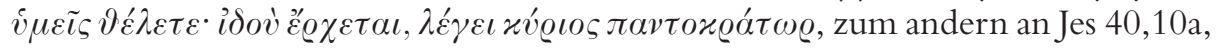

108 Zum Bezug auf Mal 3,3f. vgl. J. M. GibBs, Mark 1,1-15, Matthew 1,1-4,16, Luke 1,1-4,30, John 1,1-51. The Gospel Prologues and their Function, in: E. A. Livingstone (ed.), StEv 6 (TU 112), Berlin 1973, 154-188, hier 176.

109 Siehe o. in Absatz a). 


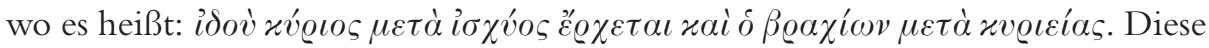
Prophetenworte lassen den markinischen Text in neuem Licht erscheinen. Beide stellen ja dem kommenden „Herrn“ eine weitere Figur zur Seite: den „Boten des Bundes“ (so Mal 3,1) bzw. „den Arm [sc. des Herrn]“ (so Jes 40,10[f.]). Es bietet sich demnach an, die genannten Figuren miteinander zu identifizieren. Da nun das Jesajawort den „Arm des Herrn“ ausdrücklich mit dessen „Stärke“ in Zusammenhang bringt, dürfte mit dem „Stärkeren“ in Mk 1,7 eben dieser „Arm des Herrn“ gemeint sein. Dann wird man die Rede vom „Weg des Herrn“ in V. 3 als Ausdruck der Erwartung verstehen, dass Gott selbst seine Herrschaft aufrichtet, wenn jener „Stärkere“ - nach Markus also Jesus - auftritt. Dabei ist gewiss vor allem seine Rolle als Verkünder und Mittler der Gottesherrschaft im Blick; das Bild vom „Hirten“ aus Jes 40,11, das der Evangelist sowohl in 6,34 als auch in 14,27 aufgreift, lässt freilich darüber hinaus an die Passion Jesu denken. Ist aber ,der Arm des Herrn“ zugleich mit dem „Boten des Bundes“ aus Mal 3,1 identisch, so muss man Mk 1,2b-c demgemäß als Prophetie der Sendung Jesu, dem Gottesvolk den Weg zu bahnen, deuten.

Diese Deutung kann durch den Rekurs auf Ex 23,20a gestützt werden. Der dort genannte „Bote“ hat ja den folgenden Versen zufolge die Aufgabe, als Träger des Namens Gottes Israel beständig an die Verpflichtungen zu erinnern, die sich aus dem von Gott gestifteten „Bund“ ergeben - auf dass es für Gott „ein königliches Priestergemeinwesen und eine heilige Völkerschaft" sei -, weil er nur ein gehorsames Israel sicher in das verheißene Land führen kann $(23,20-23) .{ }^{110}$ Dieser Bund, dessen Verpflichtungen die Israeliten einstimmig akzeptieren, wird dann durch Mose am Berg Sinai in Kraft gesetzt, indem er Opfer darbringen lässt, das Blut je zur Hälfte auf die Opferstätte gießt und über das Volk aussprengt und sagt: „Siehe, das Blut des Bundes, den der Herr gestiftet hat für euch in Bezug auf alle diese Worte" (24,4-8). Vor diesem Hintergrund erscheint der „Bote des Bundes“ in Mal 3,1 - gleichsam in Personalunion - als eschatologisches Pendant sowohl zu jenem Boten vom Sinai als auch zu Mose (auf den auch Mal 4,6[3,22] verweist!). Eben dieses Pendant gewinnt nach Markus in Jesus Gestalt; denn was Markus erzählt, entspricht, wie folgende Übersicht zeigt, mehrfach den Aussagen von Ex 23-24:

\begin{tabular}{|c|c|}
\hline Exodus & Markus \\
\hline 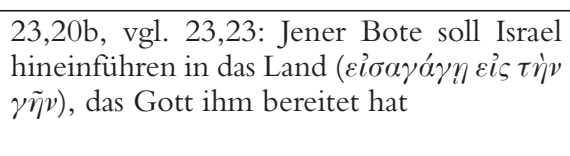 & 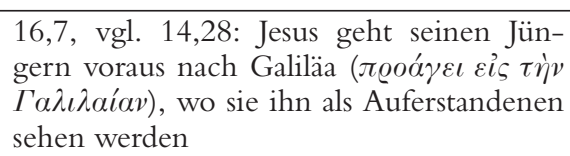 \\
\hline
\end{tabular}

110 Auf den „Bund“ und Israels Würde verweist in Ex 23,22 ${ }^{\mathrm{LXX}}$ ein Zusatz gegenüber dem MT (aus 19,5f.), der aber nur in wenigen Hss. und Übersetzungen fehlt (s. J. W. Wevers [ed.], Exodus [Septuaginta. Vetus Testamentum Graecum Auctoritate Academiae Scientiarum Gottingensis editum II/1], Göttingen 1991, z. St.) und recht alt sein dürfte (nach J. W. Wevers, Notes on the Greek Text of Exodus [SBL.SCS 30], Atlanta 1990, 370 ist er auf jeden Fall vor der Zeit des Origenes in die Textüberlieferung eingedrungen). A. vaN Der Kooij, LXX Exodus and the Figure of the High Priest, in: J. K. Aitken / K. J. Dell / B. A. Martin (edd.), On Stone and Scroll. FS Graham Ivor Davies (BZAW 420), Berlin/New York 2011, 537-549, hier 539f., hält die Passage sogar für einen Bestandteil des ursprünglichen Textes. 


\begin{tabular}{|c|c|}
\hline Exodus & Markus \\
\hline 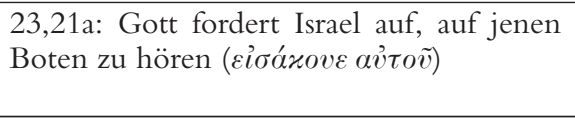 & $\begin{array}{l}\text { 9,7: Eine Himmelsstimme fordert die Jün- } \\
\text { ger auf, auf Jesus, den Sohn Gottes, zu hö- } \\
\text { ren }(\dot{\alpha} \varkappa o v \varepsilon \tau \varepsilon \alpha \dot{v} \tau o \tilde{v})^{111}\end{array}$ \\
\hline $\begin{array}{l}\text { 23,21b: Gottes „Name“ liegt auf dem Bo- } \\
\text { ten }\end{array}$ & $\begin{array}{l}\text { 11,9: Jesus ist der „im Namen des Herrn“ } \\
\text { Kommende }\end{array}$ \\
\hline 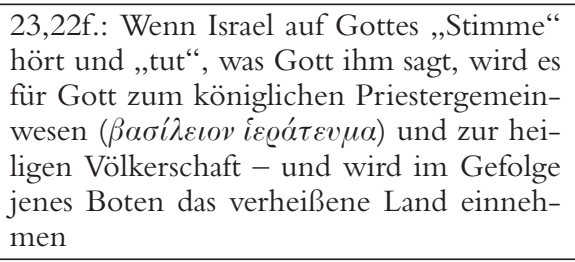 & 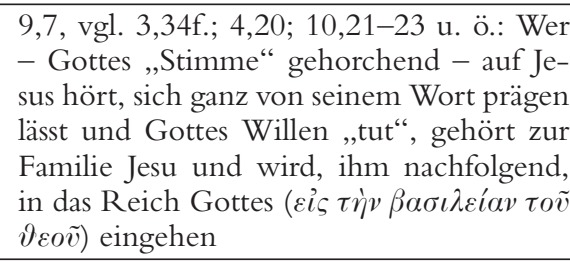 \\
\hline $\begin{array}{l}\text { 23,22.25.30: Israel wird, indem es Gottes } \\
\text { Bund „,hält" und Gott dient, das Land ,er- } \\
\text { erben““ }\end{array}$ & $\begin{array}{l}\text { 10,17-21: Wer sich zu dem einen Gott } \\
\text { bekennt, Gottes Gebote ,hält“ und Jesus } \\
\text { nachfolgt, wird ewiges Leben „,ererben“ }\end{array}$ \\
\hline $\begin{array}{l}\text { 23,32f.: Israel soll sich von fremden Göttern } \\
\text { keinesfalls zum Sündigen }(\dot{\alpha} \mu \alpha \varrho \tau \varepsilon \tilde{v} v) \text { gegen } \\
\text { Gott bringen lassen }\end{array}$ & 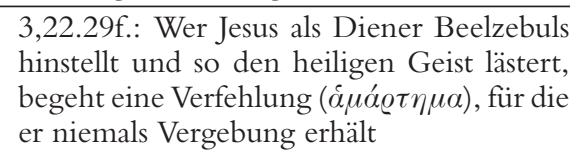 \\
\hline 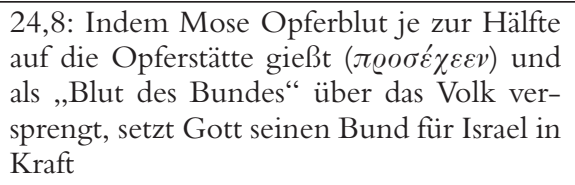 & 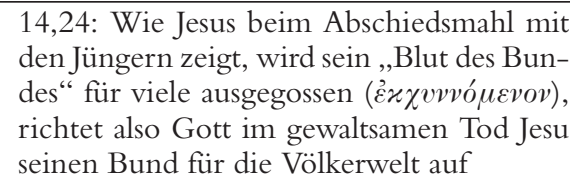 \\
\hline 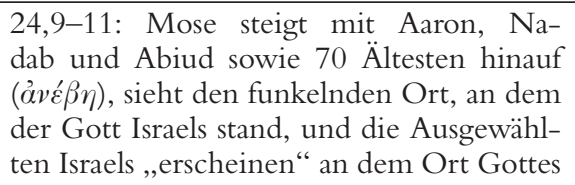 & 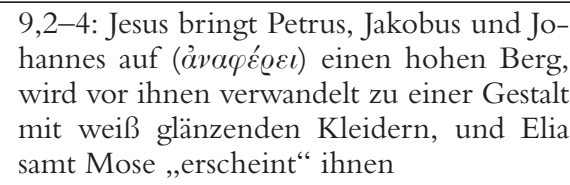 \\
\hline $\begin{array}{l}\text { 24,15f.: Mose besteigt mit Josua den Berg, } \\
\text { die „Wolke“ verhüllt den Berg, und der } \\
\text { Herr ruft Mose ,aus“ der Mitte ,der Wol- } \\
\text { ke“ }\end{array}$ & $\begin{array}{l}\text { 9,7: Eine „Wolke“ überschattet sie (sc. die } \\
\text { in V. 2-4 Genannten), und es ergeht eine } \\
\text { Stimme (sc. an die Jünger) "aus der Wolke“ }\end{array}$ \\
\hline
\end{tabular}

Es fällt jedoch auf, dass die Rolle des Boten in Ex 23 begrenzt bleibt. Man kann deshalb die Aussagen in V. $20 \mathrm{f} .23$ durchaus auch auf den Täufer beziehen; seine Rolle ist es dann, das Gottesvolk - im Hinblick auf die noch bevorstehende Inkraftsetzung des Bundes im Geschick Jesu - auf die Begegnung mit Gott vorzubereiten (Mk 1,2-6), und deshalb ist es aufgerufen, ihm zu „glauben“ $(11,30)$, gerade auch im Hinblick auf seine Äußerungen zur Würde Jesu $(1,7 \mathrm{f}$.) im Vorfeld der Taufe Jesu. Demnach wäre der „Bote des Bundes“ aus Mal 3,1 vom „Arm des Herrn“ aus Jes 40,10f. zu unterscheiden.

Die Deutung von Mk 1,2 auf die Sendung Jesu, den Weg des Gottesvolkes zu bahnen, wird allerdings durch weitere Anklänge an Aussagen und Motive aus Jes 40,21-31 im Verlauf des MkEv gestützt. So erinnern der Appell zum Hören (Mk 4,3.9.23f. u. ö.) an V. 21, die Klage über mangelndes Verstehen zumal der Jünger (Mk 4,13; 8,17 u. ö., vgl. 7,14) an V. 21.28, das Bild vom wurzellosen Menschen $(\mathrm{Mk} 4,17)$ an V. 24, die Frage nach dem angemessenen

$111 \mathrm{Vgl}$. dazu aber vor allem Dtn 18,15. 
Vergleich für die Gottesherrschaft $(\mathrm{Mk} 4,30)$ an V. 25, die Hinweise auf künftige Furcht und Ratlosigkeit der Jünger (Mk 13,5-7.11 u. ö.) an V. 27, ${ }^{112}$ die Speisungswunder (Mk 6,35-44; 8,1-9) an V. 29-31, die Ankündigung der Gefährdung selbst der „Auserwählten“ durch die letzte Bedrängnis (Mk 13,19f.) sowie das Versagen der Jünger im Kontext der Verhaftung Jesu (Mk 14,37.40.50-52) an V. 30, schließlich die Zusage der Rettung an den, der ausharrt (Mk 13,13), an V. 31.

f) Dass in Mk 1,11 nach V. 3 zum zweiten Mal eine „Stimme“ erklingt, erinnert an Jes 40,6, wo dem Textzusammenhang gemäß mit der Sequenz q

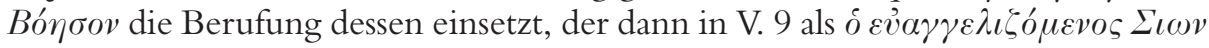
angesprochen wird; ${ }^{113}$ dabei bekennt sich dieser zum ewigen Bestand ,des Wortes unseres Gottes“ (V. 8). Das passt auch insofern zu der mit der Taufe verbundenen Bevollmächtigung Jesu, als Markus ihn im Folgenden als Prediger ,des Wortes“ (Mk 2,2; 4,33, vgl. 4,14-20) sowie als Hüter „des Wortes Gottes“ (7,13) darstellt und ihm daraufhin die Äußerung zuschreibt: „Der Himmel und die Erde werden vergehen, meine Worte aber werden nicht vergehen“ $(13,31) \cdot{ }^{114}$ Es liegt deshalb zunächst nahe, 1,3 seinerseits als Zitat einer himmlischen „Stimme“ aufzufassen. In V. 2 läge dann wohl ein Vorausverweis auf diese mit V. 3 erfolgende Beauftragung des Täufers vor - und wahrscheinlich ein Gotteswort an Jesus, da das Motiv des Voraussendens dem wiederholten Ergehen jener Stimme entspricht. Allerdings kann man aufgrund der Übereinstimmung zwischen Jes 40,6 und 40,3 im Stichwort $\beta o \alpha ́ \omega$ genauso gut zu dem Schluss kommen, dass in V. 3 ein Mensch - nach Markus dann: der Täufer - spricht, der seinen Auftrag bereits erhalten hat. ${ }^{115}$ Dann müsste Mk 1,2 auf jeden Fall als Hinweis auf dessen Sendung gedeutet werden, wobei offen bliebe, ob Gott hier zu Israel oder zu Jesus spricht.

Wahrscheinlich stellt Letzteres im Sinne des Markus aber gar keine echte Alternative dar. Die Doppelszene der Taufe und Versuchung Jesu (Mk 1,9-13) enthält ja etliche Züge, die Aussagen der Schrift über Israel anklingen lassen.

Man vergleiche in Mk 1,10f. die Rede vom „Herabkommen des Geistes“ auf Jesus nach seinem Aufstieg aus dem Wasser mit Jes 63,13f., das Motiv der Anrede durch eine „Stimme aus dem Himmel“ mit Dtn 4,36, die Bezeichnung als „,mein Sohn“ (über Ps 2,7 hinaus) mit Ex 4,22, das Attribut „geliebter Sohn“ (über Gen 22,2.12.16 hinaus) mit Jes 44,2, den Verweis auf das göttliche „Wohlgefallen an“ Jesus (über Jes 42,1 hinaus) mit Ps 43[44],4; 149, $4 .{ }^{116}$ In Mk 1,12f.

112 Die Klage Israels: „Verborgen wurde mein Weg vor Gott“, in Jes 40,27 knüpft dabei an V. 3 an!

113 Dazu s. o. Absatz b).

114 Vgl. ferner Mk 8,38, wo Jesus die Untreue gegenüber ihm und „(s)einen Worten“ zum Kriterium im endzeitlichen Gericht erklärt.

115 Auch in Jes 40,9 ist ja von der $\varphi \omega v \eta$ eines Boten Gottes die Rede.

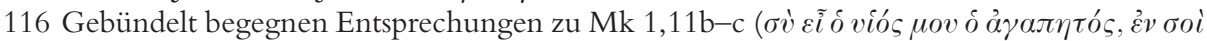

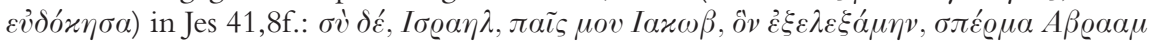

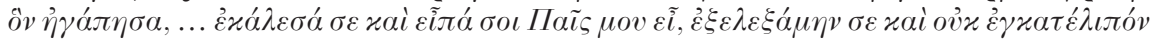
$\sigma \varepsilon$. Primär erinnert der Vers aber, wie oben notiert, zu Beginn an die Anrede, mit der Gott in Ps 2 ,seinen Gesalbten“ (V. 2) als „König auf dem Zion eingesetzt“ hat (V. 6): Yió

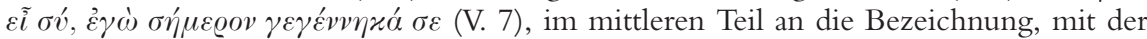
Gott Abraham gegenüber von Isaak spricht: $\delta$ viós бov $\delta \dot{\alpha} \gamma \alpha \pi \eta \tau o ́ s$, und am Ende an das 
erinnert die Verknüpfung des 40-tägigen Aufenthaltes „,in der Wüste“ mit den Motiven der Lenkung durch den „Geist“, der „Versuchung“ und der wunderbaren Versorgung an Dtn 8,2f. und 2Esdr 19 [Neh 9],20f. ${ }^{117}$

In diesen Zusammenhang gehört wohl auch Mal 3,17, wo es in ungefährer Analogie zu Mk 1,11 heißt: „Und sie [sc. die den Herrn fürchten] werden mein sein, spricht der Herr, der Allherrscher, für den Tag, den ich schaffe zur Bewahrung, und ich werde sie erwählen, wie ein Mensch seinen Sohn erwählt, der ihm dient." Demnach präsentiert Markus gerade in der Taufszene Jesus als den eschatologischen Repräsentanten Israels ${ }^{118}$ - und kann eben deshalb das Zitat in V. 2 als Wort sowohl an das Gottesvolk als auch an Jesus interpretieren.

g) Was schließlich Mk 1,14f. angeht, so rufen diese Verse erneut die Aussagen über den „Freudenboten“ in Jes 40,9 in Erinnerung. ${ }^{119}$ Dabei kann man den Ruf

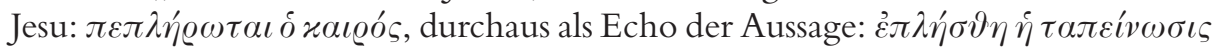
$\alpha \hat{v} \tau \tilde{\eta} \varsigma$ (Jes 40,2) verstehen - nicht nur wegen der sprachlichen Nähe, sondern vor allem deshalb, weil dieses Jesajawort, zumal im Konnex mit V. 4, seinerseits eine Art Zeitenwende anzeigt. Im Übrigen entspricht die Verbindung, die Jesus in Mk 1,15 zwischen dem Hinweis auf das Nahesein der Gottesherrschaft und dem

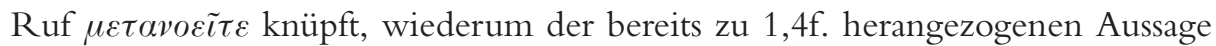
von Mal 3,7 (vgl. 3,16f.) ${ }^{120}$ - allerdings in signifikanter Umkehrung des Zusam-

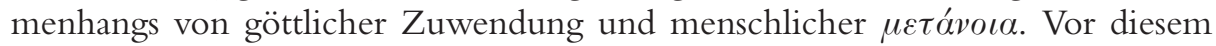
Hintergrund aber lässt sich Mk 1,3 am besten als prophetischer Hinweis auf die Berufung deuten, die an Johannes und an Jesus ergeht und der beide - auf unterschiedliche Weise - folgen: die Berufung, das Gottesvolk auf den Weg in die Gottesherrschaft zu führen.

Überblickt man den dargestellten Befund, so zeigt sich: Schon die Verse 1.4-15 aus Mk 1 enthalten zahlreiche Anklänge an Jes 40,1-11 und Mal 3,1-4,6[3,1-24]; sie machen deutlich, dass Markus die in Mk 1,2f. angeführten Jesaja- und Maleachiworte im Verein mit ihren Kontexten rezipiert und diese insgesamt als Prophetien auf das Geschehen um Johannes und Jesus gedeutet hat. In diesem Sinne weist seine Jesuserzählung dann noch etliche weitere Entsprechungen zu diversen Aspekten jener beiden Textabschnitte auf - und ruft darüber hinaus eine Reihe

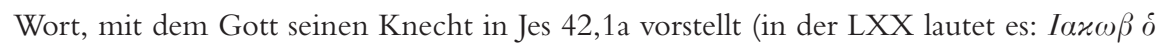

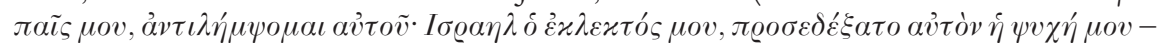
noch näher beim markinischen Text steht die [in der Hs. Q und im Codex Syrohexaplaris

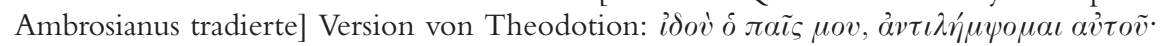

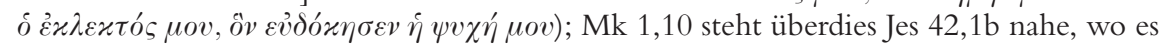

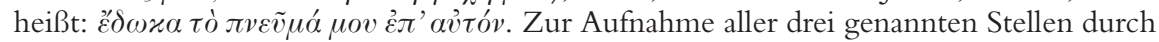
Markus vgl. Klauck, Vorspiel im Himmel?, 51-54, sowie F. J. Matera, The Prologue as the Interpretative Key to Mark's Gospel, in: JSNT 34 (1988), 3-20, hier 18.

117 In Dtn 8,2 fehlt freilich in vielen Hss. der Verweis auf die 40 Jahre. - Die nächste Parallele findet Mk 1,13 allerdings in TNaph 8,4.

118 Vgl. dazu R. E. WatTs, Isaiah's New Exodus and Mark (WUNT II/88), Tübingen 1997, 116-118.

119 Dazu s. o. bei Anm. 104.

120 Siehe o. nach Anm. 108. 
von Aussagen aus Jes 40,21-31 in Erinnerung. Außerdem bietet das MkEv in Kapitel 3-16 viele Parallelen zu Ex 23-24. Sie lassen - im Anschluss an die Rede vom „Boten des Bundes“ in Mal 3,1 - das Geschehen um (Johannes und) Jesus als das eschatologische Gegenstück zum Auftreten des Boten Gottes nach Ex 23,20-23 und zum Wirken des Mose, wie es in 24,4-16 dargestellt wird, erscheinen. ${ }^{121}$ All diese Anklänge weisen in durchaus verschiedene Richtungen. Im Grunde lassen sich alle in Abschnitt 3 erhobenen Deutungsmöglichkeiten durch je eigene Bezüge zwischen dem markinischen Umfeld von Mk 1,2f. und den Kontexten der dort angeführten Schriftworte stützen. Die Erhebung der genannten Bezüge bestätigt somit die Annahme, dass die Mehrdeutigkeit des Auftakts des MkEv intendiert ist.

Diese Mehrdeutigkeit wird im Übrigen auch durch die nächsten biblischen Analogien zu den Formulierungen im Mischzitat Mk 1,2f. illustriert: Die „Sendung“ eines göttlichen „Boten“ kann sowohl einem Einzelnen (Gen 24,7.40) als auch dem ganzen Volk Israel (Ex 33,2) zuteil werden; ${ }^{122}$ sie steht freilich stets in zumindest mittelbarem Bezug zur Landverheißung. ${ }^{123}$ Auch das „Bahnen“ oder „Bereiten“ eines ,Weges“ widerfährt mal dem Volk (Jes 57,14 ${ }^{\mathrm{Aq}, \mathrm{Th}}$ ), ${ }^{124} \mathrm{mal}$ Einzelnen (26,7, vgl. Jdt 9,6). Die Rede von „Pfaden“ Gottes bzw. des Herrn kann nicht nur einen realen Weg meinen (so in Ps 76[77],20 mit Blick auf den Exodus), sondern auch, und zwar öfter, das Leben nach Gottes Geboten (vgl. Ps 16[17],5; 24[25],4; Mi 4,2; Jer 6,16; Dan $\left.4,34[37]^{\text {Th }}\right)$. Letzteres ist meist auch dann im Blick, wenn von „geraden Pfaden“ oder „... Wegen“ gesprochen wird (Tob 4,19 ${ }^{\mathrm{BA}}$; Ps 26[27],11; Spr 2,19; Sap 10,10; Jes 33,15, vgl. Sir 37,15[19]); in Jes 45,13 scheint dieser Ausdruck jedoch auf das Gelingen des Wirkens dessen angewandt zu sein, den Gott erweckt hat, um die Gefangenschaft seines Volkes zu wenden.

\section{Zur Funktion von $\mathrm{Mk}$ 1,2f. für die Lektüre des $\mathrm{MkEv}$}

Die Untersuchung der Zitatkombination Mk 1,2f. hinsichtlich ihrer syntaktischen und referentiellen Einbindung in das MkEv, ihrer Parallelen in den beiden anderen synoptischen Evangelien und ihrer Grundlage in den Schriften der Septuaginta hat zu dem Ergebnis geführt, dass diesem Zitat aus exegetischer Sicht eine nicht aufzuhebende Mehrdeutigkeit eignet. Weil dabei auf verschiedenen Betrachtungsebenen jeweils gegenläufige Beobachtungen zu machen waren, hat sich mehr und mehr die Annahme aufgedrängt, dass diese Mehrdeutigkeit Ausdruck nicht eines Missgeschicks, sondern der Textpragmatik ist. In der Tat ist das Schriftzitat infolge seiner auktorialen - und darin im MkEv einzigartigen - Verwendung und seiner Positionierung am Anfang des Werkes geeignet, den Leserinnen und Lesern eine

121 Die kategoriale Differenz der im MkEv erkennbaren Bezüge auf Mal 3-4 ${ }^{\mathrm{LXX}}$ und Ex 23-24 ${ }^{\text {LXX }}$ entspricht dem Befund, dass Mal 3,1 und nicht Ex 23,20 die Basis des Zitats in Mk 1,2 bildet (s. o. bei und in Anm. 98).

122 Dazu s. o. bei und in Anm. 85 sowie bei Anm. 96.

123 Das gilt auch für Mal 3-4 $4^{\mathrm{LXX}}$, wie 3,8-12 zeigt. Ausnahmen bilden allein Dan 4,10[13] und 20[23], wo von der Sendung eines Engels im Rahmen einer Visionsschilderung erzählt wird.

124 Vergleichbare Aussagen mit $\pi$ oı́́ $\omega$ o. ä. bieten Ps 79[80],10; Jes 43,19; 62,10, ferner Jes 43,16; 51,10 im Bezug auf den Durchzug durchs Meer. 
bestimmte Art der Wahrnehmung der markinischen Jesuserzählung nahe zu legen. Die Kombination des Mischzitats aus Mal 3,1a und Ex 23,20a mit dem Zitat aus Jes 40,3 dient - im Zusammenhang mit der Kopfzeile Mk 1,1 - als eine Leseanweisung, deren schillernder Sinn zu wiederholter Betrachtung nötigt und dabei immer wieder neue Perspektiven auf die Jesusgeschichte eröffnet. Etwas vereinfacht lassen sich zunächst folgende Wahrnehmungsstufen unterscheiden:

\begin{tabular}{|c|c|}
\hline $\begin{array}{l}\text { die markinische Jesuserzählung } \\
\text { im Lichte von Mal 3,1a/Ex 23,20a und Jes 40,3 }\end{array}$ & $\begin{array}{c}\text { der weitere biblische } \\
\text { Hintergrund }\end{array}$ \\
\hline $\begin{array}{l}\text { 1) Wie die Schrift sagt, liegt der Ursprung der Evange- } \\
\text { liumsverkündigung Jesu }{ }^{a} \text { in der Sendung des Täufers, der als } \\
\text { Vorläufer }^{b} \text { und Herold }{ }^{c} \text { Jesu auftritt und das jüdische Volk in der } \\
\text { Wüste dazu aufruft, sich auf das Kommen Gottes vorzubereiten } \\
\text { (Mk 1,1.2-8). }\end{array}$ & $\begin{array}{l}\text { a) Jes 40,2.6-9 } \\
\text { b) Jes 40,2; Mal 4,4f. } \\
\text { c) Jes 40,10f. } \\
\text { d) Mal 3,1.3f.7; 4,4f. }\end{array}$ \\
\hline $\begin{array}{l}\text { 2) Wie die Schrift sagt, liegt der Ursprung der Evange- } \\
\text { liumsverkündigung Jesu }{ }^{\mathrm{a}} \text { in der Sendung des Täufers, der als } \\
\text { Vorläufer }^{\mathrm{b}} \text {, Herold und Mittler der Bevollmächtigung Jesu* auf- } \\
\text { tritt und damit seiner Berufung folgt, in der Wüste das Kommen } \\
\text { des Herrn im Wirken seines Repräsentanten Jesus Christus } \\
\text { vorzubereiten }^{\mathrm{d}} \text { (Mk 1,1.2-11). }\end{array}$ & $\begin{array}{l}\text { a) Jes 40,2.6-9 } \\
\text { b) Jes 40,2 } \\
\text { * [Mal 3,17 etc.] } \\
\text { c) Jes 40,10f. } \\
\text { d) Mal 3,1; Ex 23,20f. }\end{array}$ \\
\hline $\begin{array}{l}\text { 3) Der Ursprung der Evangeliumsverkündigung Jesu }{ }^{\mathrm{a}} \text { ent- } \\
\text { spricht dem Zeugnis der Schrift: Indem Johannes als Vorläufer } \\
\text { und Herold Jesu auftritt, Jesus aber sich daraufhin der Taufe } \\
\text { unterzieht* und der Versuchung durch Satan widersteht, erfüllt } \\
\text { sich die Ankündigung eines Wegbahners für Jesus und kom- } \\
\text { men beide ihrer Berufung nach }{ }^{\mathrm{c}} \text {, in der Wüste die Ankunft der } \\
\text { Herrschaft Gottes im Zuge des Wirkens Jesu }{ }^{\mathrm{d}} \text { vorzubereiten }^{\mathrm{e}} \\
\text { (Mk 1,1-3.4-13). }\end{array}$ & $\begin{array}{l}\text { a) Jes 40,2.6-9 } \\
\text { b) Jes 40,2 } \\
\text { * [Mal 3,17 etc.] } \\
\text { c) Mal 3,7.16f. } \\
\text { d) Jes 40,10f. } \\
\text { e) Mal 3,1; Ex 23,20f. }\end{array}$ \\
\hline $\begin{array}{l}\text { 4) Die Grundlegung des Evangeliums von Jesus Christus }{ }^{\mathrm{a}} \text { ent- } \\
\text { spricht dem Zeugnis der Schrift: Indem Jesus - im Anschluss } \\
\text { an das Wirken }{ }^{\mathrm{b}} \text { und das Geschick des Täufers, zugleich ihm äh- } \\
\text { nelnd und es überbietend }{ }^{\mathrm{c}}-\text { das endzeitliche Kommen Gottes } \\
\text { verkündet, das Gottesvolk zur Umkehr ruft und seinen Jün- } \\
\text { gern zuerst nach Jerusalem vorausgeht }{ }^{\mathrm{d}} \text {, dann als Auferstande- } \\
\text { ner nach Galiläa, bahnt er seinen Nachfolgern den Weg }{ }^{\mathrm{e}} \text {, im } \\
\text { Glauben an das Evangelium den Weg in das Reich Gottes zu } \\
\text { begehen (Mk 1,1-3; 1,4-16,8). }\end{array}$ & $\begin{array}{l}\text { a) Jes 40,5b.9 } \\
\text { b) Jes 40,2; Mal 4,4f. } \\
\text { c) Mal 3,7.16f. } \\
\text { d) Mal 3,1; Jes 40,9 } \\
\text { e) Mal 3,1; Jes 40,10f.; } \\
\text { Ex 23,20-24,16; } \\
\text { Jes 40,21-31 }\end{array}$ \\
\hline
\end{tabular}

Gewisse Inkonsistenzen bei den Rückbezügen der anschließenden Erzählung auf Mk 1,1.2f. leiten dazu an, bei der Lektüre von einer Stufe zur nächsten fortzuschreiten. Hat man sich aber auf diese Weise immer tiefer in das Verständnis der markinischen Jesuserzählung einführen lassen und dabei gelernt, sie insgesamt und gerade angesichts ihres offenen Schlusses als Grundlegung des Evangeliums von Jesus Christus zu verstehen, ${ }^{125}$ so wird man von diesem offenen Schluss - in

125 Vgl. zum letztgenannten Gesichtspunkt H. MerkLein, Die Jesusgeschichte - synoptisch gelesen (SBS 156), Stuttgart 1994, 223: „Der Leser wird bewußt an diesen Ort [sc. das 
Verbindung mit erneuten Härten im Verhältnis zum Anfang des MkEv - an den Anfang zurückkehren, um ihn und im Anschluss daran die Jesusgeschichte des Markus erneut wahrzunehmen. Dabei wird man noch einmal andere Entdeckungen zum Verhältnis der Kopfzeile und des Zitats zum Folgenden machen; die erste Möglichkeit dazu lässt sich in Kürze, wie folgt, charakterisieren:

5) Die Grundlegung des Evangeliums von Jesus Christus ${ }^{\mathrm{a}}$ in der von Markus erzählten Geschichte Jesu beginnt, der Schrift entsprechend, damit, dass der Täufer seine Aufgabe erfüllt, das Gottesvolk auf die Begegnung mit Gott vorzubereiten ${ }^{\mathrm{b}}$ (Mk 1,1.2-6).

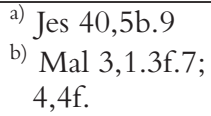

Indes kann auch diese Wahrnehmung nicht voll befriedigen, sodass sie ihrerseits über sich hinausweist und zu weiterer Lektüre des MkEv von seinem Anfang her nötigt.

Die Frage, wer wem gemäß Mk 1,2f. den Weg bahnt oder bereitet, lässt sich also nicht einlinig beantworten. Der Täufer tut es für das Gottesvolk und/oder Jesus Christus; Jesus Christus tut es für das Gottesvolk; das Gottesvolk tut es für Gott selbst, der seine Herrschaft durch den Täufer anbahnen, im Wirken und Geschick Jesu Christi dann anfänglich präsent werden lässt: All diese Antworten sind je für sich genommen treffend, aber nicht hinreichend; all diese Antworten gehören also zusammen, führen jedoch auch gemeinsam noch zu keinem schlüssigen Ergebnis. Denn ,,der Weg des Herrn“ zur Aufrichtung der Gottesherrschaft, der mit dem Auftreten des Täufers seinen Anfang nimmt, ist noch nicht am Ende. Sein Ziel wird er erst dadurch erreichen, dass die letzten „Boten“ erscheinen: die „Boten“, die den „Menschensohn“ begleiten werden, ,,wenn er kommt in der Herrlichkeit seines Vaters“ (8,38), und die er ,dann aussenden wird“, um selbst „die Auserwählten zusammen[zu]führ[en] aus den vier Windrichtungen, vom Ende der Erde bis zum Ende des Himmels“ (13,27).

Bis dahin ist der Auftrag: „Bereitet den Weg des Herrn!“, nicht abschließend erfüllt. Genau dies zeigt der Auftakt in seinem spannungsvollen Verhältnis zum Rest der markinischen Jesuserzählung. So sorgt er dafür, dass man als Leser/in dem von Markus dargestellten Jesus auf der Spur bleibt - und eben damit auf dem Weg, den Jesus Christus im Gefolge des Täufers vorangegangen ist, auf dem Weg ,,in das Leben“.

geöffnete, leere Grab Jesu] geführt, wo die im Markusevangelium erzählte Geschichte zur letzten Ruhe kommt, ... um dort die Botschaft zu hören, die eine abschließende Retrospektive unmöglich macht und die Geschichte aus der fortdauernden und zukunftsweisenden Perspektive des Kerygmas zu lesen lehrt.“ 


\section{Zur Bedeutung der Septuaginta für die Exegese des Neuen Testaments}

Die vorgelegte Analyse von Mk 1,2f. und seinem Umfeld erlaubt es, einige Konsequenzen hinsichtlich der Bedeutung der Septuaginta für die Exegese des Neuen Testaments zu ziehen. Diese Konsequenzen seien nachstehend in Form von Thesen benannt:

a) Wie der Auftakt des MkEv programmatisch anzeigt, soll es von Anfang an im Zusammenhang mit ,den Schriften“ (Mk 14,49) gelesen und kann es überhaupt nur im Anschluss an sie verstanden werden. Dies gilt in ähnlicher Weise für das ganze Neue Testament, bezeugt es doch in all seinen Teilen ein Geschehen zwischen Himmel und Erde, durch das die Verheißungen Gottes, die in jenen Schriften aufgezeichnet sind, zur Erfüllung kommen - und dass Letztere die Sprache, in der das neutestamentliche Zeugnis ergeht, tiefgreifend geprägt haben. Die genaue Kenntnis jener Schriften und die Beachtung des genannten Zusammenhangs sind deshalb für die Exegese des Neuen Testaments von grundlegender Bedeutung.

b) Wie auch und gerade in Mk 1,2f. deutlich wird, bezieht sich das Neue Testament (fast durchweg) auf die griechischen Versionen jener Schriften, die später zur so genannten Septuaginta zusammengestellt worden sind. Diese Versionen haben gegenüber dem hebräischen Original ihr eigenes sprachliches und theologisches Profil. Allerdings setzt das Neue Testament eine noch im Fluss befindliche Überlieferung ihres Textes voraus; und die schloss diverse, z. T. heute nicht gesondert erhaltene Fassungen ein, in denen die griechische Übersetzung sekundär an die hebräischen Originale angenähert worden war. Zudem nimmt es auf Auslegungstraditionen Bezug, die am hebräischen Text entwickelt worden sind. Eine sachgerechte Exegese des Neuen Testaments ist deshalb ohne eine (möglichst) gute Kenntnis der Septuaginta, ihrer handschriftlichen Überlieferung, ihrer Revisionen sowie ihres Verhältnisses zur Hebräischen Bibel und zu deren Auslegungsgeschichte im antiken Judentum nicht möglich.

c) Wie man an Mk 1,2f. sehen kann, greift das Neue Testament einzelne, für die Übermittlung seines Zeugnisses besonders wichtige Worte aus den „Schriften“ in Form von Zitaten auf. Um die Funktion, den Sinn und die Bedeutung solch eines Zitats zu erfassen, müssen jeweils zunächst seine syntaktische und referentielle Einbettung in das neue literarische Umfeld sowie die Genese und Eigenart seiner Textgestalt geklärt werden; dazu gehört ggf. (wie im vorliegenden Fall) auch die Beschreibung des Verhältnisses, in das verschiedene, miteinander kombinierte oder vermischte Schriftworte zueinander gestellt worden sind. Hilfreich ist überdies die Auswertung der frühchristlichen Wirkungsgeschichte. Zu einem wirklichen Verstehen des mit einem Zitat versehenen neutestamentlichen Abschnitts bedarf es jedoch darüber hinaus der Aufhellung des Zusammenhangs, der - ausweislich sprachlich-sachlicher Konvergenzen - zwischen diesem Abschnitt und dem ursprünglichen Kontext besteht. Dafür müssen dann in der Regel auch Anspielungen auf weitere biblische Prätexte und Berührungen mit entsprechenden Auslegungstraditionen aufgespürt und ausgewertet werden. Erst angesichts des 
Netzes aus Schriftworten, Kontexten und Deutungen, in das ein neutestamentlicher Text - teils an Vorhandenes anschließend, teils neue Verbindungen knüpfend - eingebunden ist, werden sein Sinngehalt und seine kommunikative Absicht klar erkennbar.

d) Wie auch und gerade die Zitatkombination $\mathrm{Mk}$ 1,2f. zutage treten lässt, liegt der neutestamentlichen Verwendung von Worten und Abschnitten aus den „Schriften“ ein neues Verständnis dieser Worte und Abschnitte zugrunde: Sie erscheinen auf einmal als Zeugnisse und Interpretamente des Christusgeschehens. Dabei knüpft das Neue Testament formal an eine ältere, im antiken Judentum verschiedentlich bezeugte und nicht zuletzt schon in manchen Büchern der Septuaginta selbst belegte Auslegungsweise an, bei der die „Schriften“ als Vorausverweis auf die eigene zeit- und heilsgeschichtliche Situation gelesen und genutzt wurden. ${ }^{126}$ Der Sache nach ist die im Neuen Testament (und zeitgenössischen frühchristlichen Texten) vollzogene Erfüllungsinterpretation in seinem Umfeld freilich singulär. Ihre Besonderheit ergibt sich nicht zuletzt daraus, dass hier die anfängliche Erfüllung der endzeitlichen Heilszusagen Gottes für Israel und die Weltvölker durch ein neues Heilshandeln Gottes reklamiert wird. Dies aber führt zwangsläufig zu einer in sich vielfältigen und nie ganz konsistenten Deutung der „Schriften“. Da „,der Weg des Herrn“" sein letztes Ziel noch nicht erreicht hat, bleibt der Sinn der „Schriften“ im Vollzug der Deutung auf das Christusgeschehen gleichsam in der Schwebe. Deshalb müssen sie stets aufs Neue gelesen und auf ihre Beziehung zu diesem Geschehen befragt werden. Die Frage, wer wem den Weg bereitet, ist also auch im Blick auf das Verhältnis zwischen den beiden Testamenten der christlichen Bibel nicht einlinig zu beantworten. Die Kenntnis der Septuaginta (und der Hebräischen Bibel) führt zum Verstehen des Neuen Testaments; die Lektüre des Neuen Testaments führt zu einem neuen Verständnis der „Schriften“: Beide Antworten sind für sich genommen treffend, aber nicht hinreichend; beide gehören zusammen, ohne doch gemeinsam schon zu einem schlüssigen Ergebnis zu führen. Bis zur Vollendung der Gottesherrschaft wird daher das Hören der Nachfolger Jesu auf den Ruf „Bereitet den Weg des Herrn!“ eine fortwährende Bemühung der christlichen Bibelwissenschaftler um die Aufhellung des Zusammenhangs zwischen der Septuaginta und dem Neuen Testament einschließen. ${ }^{127}$

126 Vgl. exemplarisch F. WiLK, „Vision wider Judäa und wider Jerusalem“ (Jes 1 LXX). Zur Eigenart der Septuaginta-Version des Jesajabuches, in: W. Kraus / K.-W. NiEbuHr (edd.), Frühjudentum und Neues Testament im Horizont Biblischer Theologie (WUNT 162), Tübingen 2003, 15-35, hier 33-35.

127 Für Rat und Hilfe danke ich Markus Öhler (Wien) und Frank Schleritt (Göttingen). 

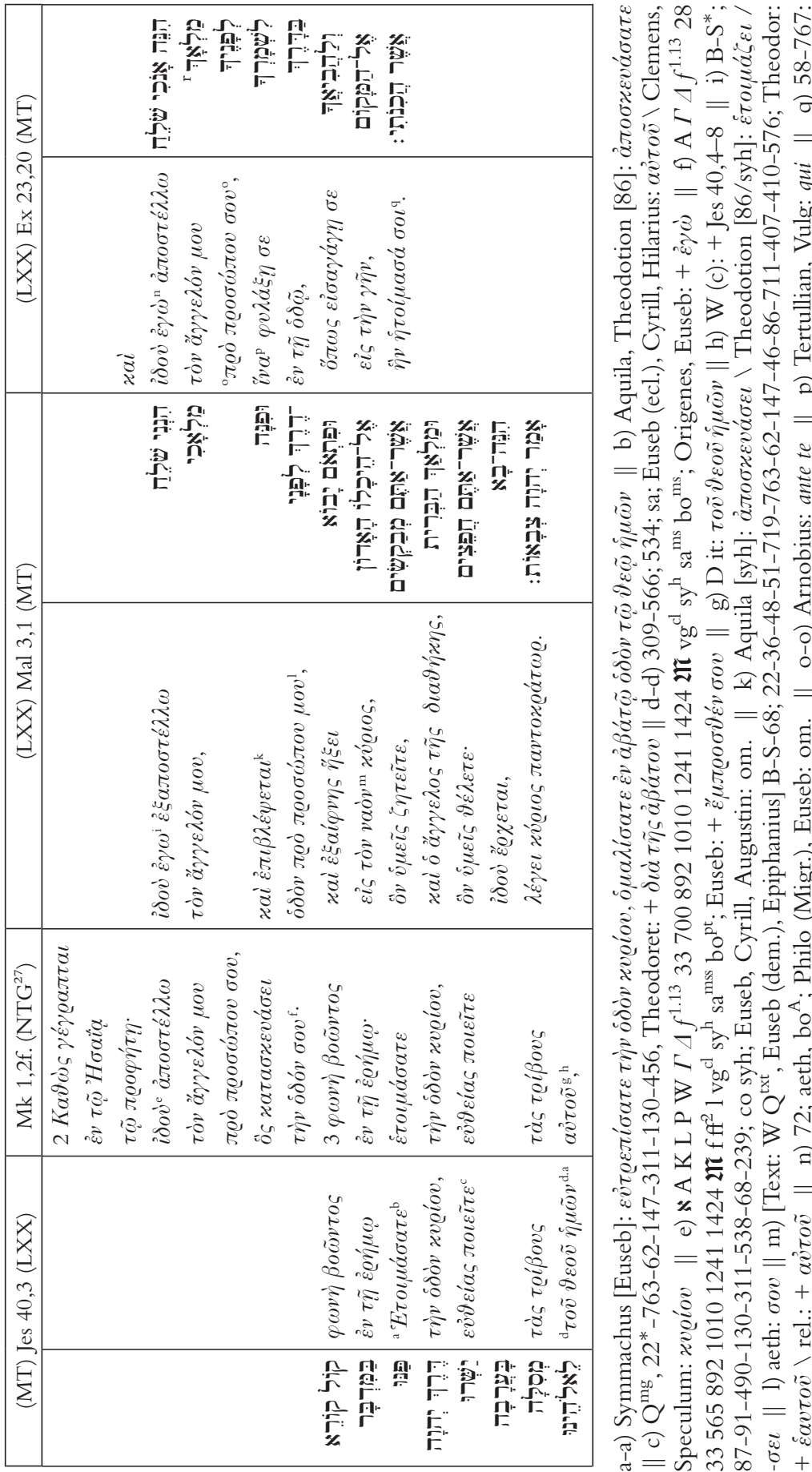

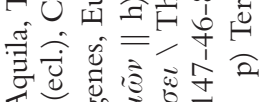

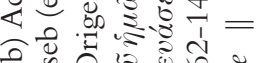

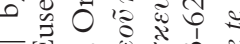
उิ

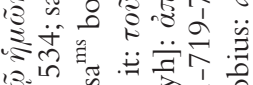

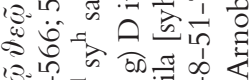

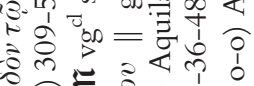

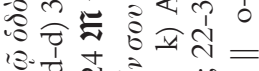

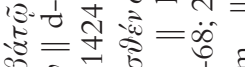

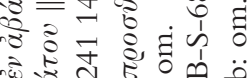

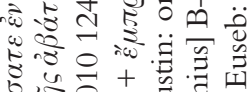

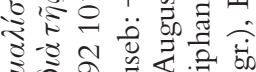

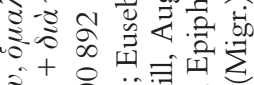

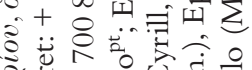

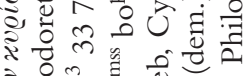

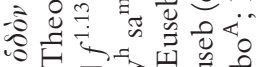

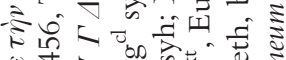

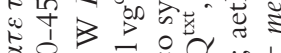
ชัช

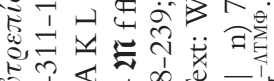

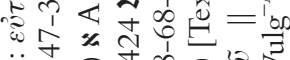

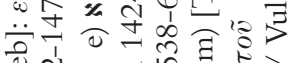

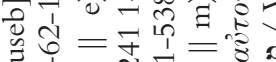

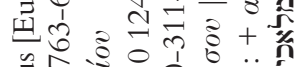
䒕 제유

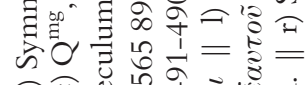

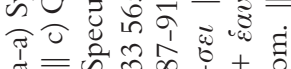




\section{Literatur}

ArNold, G., Mk $1_{1}$ und Eröffnungswendungen in griechischen und lateinischen Schriften, in: ZNW 68 (1977), 123-127.

Boring, E., Mark 1:1 and the Beginning of the Gospel, in: Semeia 52 (1980), 43-81.

Dormeyer, D., Mk 1,1-15 als Prolog des ersten idealbiographischen Evangeliums von Jesus Christus, in: Biblical Interpretation 5 (1997), 181-211.

ECKeY, W., Das Markusevangelium. Orientierung am Weg Jesu. Ein Kommentar, Neukirchen-Vluyn 1998.

FeneberG, W., Der Markusprolog. Studien zur Formbestimmung des Evangeliums (StANT 36), München 1974.

Fuchs, A., Exegese im elfenbeinernen Turm. Das quellenkritische Problem von Mk 1,2-8 par Mt 3,1-12 par Lk 3,1-17 in der Sicht der Zweiquellentheorie und von Deuteromarkus, in: SNTU 20 (1995), 23-149.

Gibis, J. M., Mark 1,1-15, Matthew 1,1-4,16, Luke 1,1-4,30, John 1,1-51. The Gospel Prologues and their Function, in: E. A. Livingstone (ed.), StEv 6 (TU 112), Berlin 1973, 154-188.

GnilkA, J., Das Evangelium nach Markus. 1. Teilband: Mk 1-8,26 (EKK II/1), Zürich/Neukirchen-Vluyn ${ }^{4} 1994$.

Hanhart, R., Septuaginta, in: W. H. Schmidt / W. Thiel / R. Hanhart (edd.), Altes Testament (GKT 1), Stuttgart 1989, 176-196.

Hatina, T. R., In Search of a Context. The Function of Scripture in Mark's Narrative (JSNT.S 232), Sheffield 2002.

Kampling, R., Israel unter dem Anspruch des Messias. Studien zur Israelthematik im Markusevangelium (SBB 25), Stuttgart 1992.

Katz, P., Wie einer der Propheten? Das biblische Markusevangelium als Darbietung eines «Vorevangeliums», in: ThZ 58 (2002), 46-60.

KLaucK, H.-J., Vorspiel im Himmel? Erzähltechnik und Theologie im Markusprolog (BThSt 32), Neukirchen-Vluyn 1997.

Kooij, A. van Der, LXX Exodus and the Figure of the High Priest, in: J. K. Aitken / K. J. Dell / B. A. Martin (edd.), On Stone and Scroll. FS Graham Ivor Davies (BZAW 420), Berlin/New York 2011, 537-549.

LAmbrecht, J., John the Baptist and Jesus in Mark 1.1-15. Markan Redaction of Q?, in: NTS 38 (1992), 357-384.

Lausberg, H., Minuscula philologica (III): Die prooemiale Periode des Evangeliums nach Markus (1,2-4), in: NAWG.PH 1979, 69-77.

Lührmann, D., Das Markusevangelium (HNT 3), Tübingen 1987.

Marcus, J., The Way of the Lord. Christological Exegesis of the Old Testament in the Gospel of Mark, Edinburgh 1992.

Matera, F. J., The Prologue as the Interpretative Key to Mark's Gospel, in: JSNT 34 (1988), 3-20.

Merendino, R. P., Testi anticotestamentari in Mc 1,2-8, in: RivBib 35 (1987), 3-25.

Merklein, H., Die Jesusgeschichte - synoptisch gelesen (SBS 156), Stuttgart 1994.

Metzger, B. M., A Textual Commentary to the Greek New Testament, Stuttgart ${ }^{2} 1994$.

ÖHLER, M., Elia im Neuen Testament. Untersuchungen zur Bedeutung des alttestamentlichen Propheten im frühen Christentum (BZNW 88), Berlin/New York 1997.

Robinson, J. M. / P. Hoffmann / J. S. Kloppenborg (edd.), The Critical edition of Q. Synopsis including the Gospels of Matthew and Luke, Mark and Thomas with English, German and French Translations of Q and Thomas, Leuven/Minneapolis 2000. 
Sankey, P. J., Promise and Fulfilment: Reader-Response to Mark 1.1-15, in: JSNT 58 (1995), 3-18.

Steichele, H. J., Der leidende Sohn Gottes. Eine Untersuchung einiger alttestamentlicher Motive in der Christologie des Markusevangeliums (BU 14), Regensburg 1980.

Strack, H. L. / P. Billerbeck, Kommentar zum Neuen Testament aus Talmud und Midrasch, Vol. 1, München ${ }^{2} 1956$.

Tolbert, M. A., Sowing the Gospel. Mark's World in Literary-Historical Perspective, Minneapolis 1989.

van Iersel, B., Markus. Kommentar, Düsseldorf 1993.

Walter, N., Johannes und Jesus - zwei eschatologische Propheten. Das Selbstbild Jesu im Spiegel seines Bildes vom Täufer nach Q/Lk 7,24-35, in: U. H. J. KörTnER (ed.), Jesus im 21. Jahrhundert. Bultmanns Jesusbuch und die heutige Jesusforschung, NeukirchenVluyn 2002, 135-151.

- Mk 1,1-8 und die ,agreements“ von Mt 3 und Lk 3. Stand die Predigt Johannes des Taufers in Q?, in: F. Van Segbroeck et al. (edd.), The Four Gospels 1992. FS Frans Neirynck, Vol. 1 (BETL 100), Leuven 1992, 457-478.

WATts, R. E., Isaiah's New Exodus and Mark (WUNT II/88), Tübingen 1997.

Weber, R., Christologie und „Messiasgeheimnis“: ihr Zusammenhang und Stellenwert in den Darstellungsintentionen des Markus, in: EvTh 43 (1983), 108-125.

Wevers, J. W. (ed.), Exodus (Septuaginta. Vetus Testamentum Graecum Auctoritate Academiae Scientiarum Gottingensis editum II/1), Göttingen 1991.

- Notes on the Greek Text of Exodus (SBL.SCS 30), Atlanta 1990.

Wilk, F., Die Bedeutung des Jesajabuches für Paulus (FRLANT 179), Göttingen 1998.

- Ein für alle Mal!? Zur Verbindlichkeit der Ehe im Neuen Testament, in: LVK-Forum (2/2007), 34-44.

- Jesus und die Völker in der Sicht der Synoptiker (BZNW 109), Berlin/New York 2002.

- Paulus als Nutzer, Interpret und Leser des Jesajabuches, in: S. Alkier / R. B. Hays (edd.), Die Bibel im Dialog der Schriften. Konzepte intertextueller Bibellektüre (NET 10), Tübingen/Basel 2005, 93-116.

- „Vision wider Judäa und wider Jerusalem“ (Jes 1 LXX). Zur Eigenart der SeptuagintaVersion des Jesajabuches, in: W. Kraus / K.-W. Niebuhr (edd.), Frühjudentum und Neues Testament im Horizont Biblischer Theologie (WUNT 162), Tübingen 2003, 15-35.

Ziegler, J. (ed.), Isaias (Septuaginta. Vetus Testamentum Graecum Auctoritate Academiae Scientiarum Gottingensis editum XIV), Göttingen ${ }^{3} 1983$.

- Untersuchungen zur Septuaginta des Buches Isaias (ATA 12,3), Münster 1934.

Zmijewski, J., Markinischer «Prolog» und Täufertradition. Eine Untersuchung zu Mk 1,1-8, in: SNTU 18 (1993), 41-62. 
